\title{
Application of Laser-Induced, Deep UV Raman Spectroscopy and Artificial Intelligence in Real-Time Environmental Monitoring-Solutions and First Results
}

\author{
Claudia Post ${ }^{1, *(\mathbb{D})}$, Simon Brülisauer ${ }^{2, *}$, Kryss Waldschläger ${ }^{3}{ }^{\circledR}$, William Hug ${ }^{4}$, Luis Grüneis ${ }^{1}$, Niklas Heyden ${ }^{1}$, \\ Sebastian Schmor ${ }^{1}$, Aaron Förderer ${ }^{1}$, Ray Reid ${ }^{4}$, Michael Reid ${ }^{4}$, Rohit Bhartia ${ }^{4}$, Quoc Nguyen ${ }^{4}$, \\ Holger Schüttrumpf ${ }^{3}$ iD and Florian Amann ${ }^{1}$
}

Citation: Post, C.; Brülisauer, S.; Waldschläger, K.; Hug, W.; Grüneis, L.; Heyden, N.; Schmor, S.; Förderer,

A.; Reid, R.; Reid, M.; et al. Application of Laser-Induced, Deep

UV Raman Spectroscopy and Artificial Intelligence in Real-Time Environmental MonitoringSolutions and First Results. Sensors 2021, 21, 3911. https://doi.org/ $10.3390 / \mathrm{s} 21113911$

Academic Editor: Gianluca Gagliardi

Received: 6 April 2021

Accepted: 1 June 2021

Published: 5 June 2021

Publisher's Note: MDPI stays neutral with regard to jurisdictional claims in published maps and institutional affiliations.

Copyright: (c) 2021 by the authors Licensee MDPI, Basel, Switzerland. This article is an open access article distributed under the terms and conditions of the Creative Commons Attribution (CC BY) license (https:// creativecommons.org/licenses/by/ $4.0 /)$.
1 Department of Engineering Geology and Hydrogeology, RWTH Aachen University, Lochnerstr. 4-20, 52064 Aachen, Germany; luis.grueneis@rwth-aachen.de (L.G.); niklas.heyden@rwth-aachen.de (N.H.); sebastian.schmor@rwth-aachen.de (S.S.); aaron.foerderer@rwth-aachen.de (A.F.); amann@lih.rwth-aachen.de (F.A.)

2 Artha, Wagistrasse 21, CH-8952 Schlieren, Switzerland

3 Institute of Hydraulic Engineering and Water Resources Management, RWTH Aachen University, Mies-van-der-Rohe-Str. 17, 52056 Aachen, Germany; waldschlaeger@iww.rwth-aachen.de (K.W.); sekretariat@iww.rwth-aachen.de (H.S.)

4 Photon Systems Inc., 1512 Industrial Park St., Covina, CA 91722-3417, USA; w.hug@photonsystems.com (W.H.); r.reid@photonsystems.com (R.R.); m.reid@photonsystems.com (M.R.); r.bhartia@Photonsystems.com (R.B.); q.nguyen@Photonsystems.com (Q.N.)

* Correspondence: cpost@lih.rwth-aachen.de (C.P.); simon.bruelisauer@artha-x.com (S.B.); Tel.: +49-241-809-6777 (C.P.); +41-442-153-505 (S.B.)

\begin{abstract}
Environmental monitoring of aquatic systems is the key requirement for sustainable environmental protection and future drinking water supply. The quality of water resources depends on the effectiveness of water treatment plants to reduce chemical pollutants, such as nitrates, pharmaceuticals, or microplastics. Changes in water quality can vary rapidly and must be monitored in real-time, enabling immediate action. In this study, we test the feasibility of a deep UV Raman spectrometer for the detection of nitrate/nitrite, selected pharmaceuticals and the most widespread microplastic polymers. Software utilizing artificial intelligence, such as a convolutional neural network, is trained for recognizing typical spectral patterns of individual pollutants, once processed by mathematical filters and machine learning algorithms. The results of an initial experimental study show that nitrates and nitrites can be detected and quantified. The detection of nitrates poses some challenges due to the noise-to-signal ratio and background and related noise due to water or other materials. Selected pharmaceutical substances could be detected via Raman spectroscopy, but not at concentrations in the $\mu \mathrm{g} / \mathrm{l}$ or $\mathrm{ng} / \mathrm{l}$ range. Microplastic particles are non-soluble substances and can be detected and identified, but the measurements suffer from the heterogeneous distribution of the microparticles in flow experiments.
\end{abstract}

Keywords: environmental monitoring; machine learning; data processing; real-time water analysis; DUV Raman/fluorescence spectroscopy

\section{Introduction}

Repeated sampling of the aquatic environment is a fundamental component of environmental research [1]. Especially for pollutants whose concentrations should remain low or are to be reduced in the future, monitoring is indispensable, as this is the only way to detect changes in environmental pollution over time and to quantify the effect of measures and management strategies [1,2]. Examples of such monitoring activities are (1) the repeated quantification of nitrate and nitrogen levels in the fluvial environment [3], (2) the frequent quantification of pharmaceuticals, bacteria or viruses in the fluvial environment 
or in the effluent of wastewater treatment plants [4-6], and (3) the systematic quantification of plastic waste in the marine and fluvial environment [7-9].

The European Water Framework Directive (WFD) and the Marine Strategy Framework Directive (MSFD) request a monitoring program to examine the quality of rivers and oceans. The WFD demands regular measurements of a variety of substances, currently excluding pharmaceuticals and microplastics. However, the need for sustainable environmental management and a growing awareness of the potential negative impact of micropollutants on ecosystems requires including these substances in the WFD and the MSFD [10]. Based on the requirements of the WFD/MSFD and the emerging need for an extended list of micropollutants for future monitoring activities, a variety of analytical methods exist [11-13]. However, the conventional methods are time-consuming (e.g., due to sample preparation requirements), selective, susceptible to ionic interference, or require expensive sorbents that may be harmful to the environment [11]. It is therefore desirable to have a measuring device that can measure and identify all substances at the same time, without using environmentally harmful and expensive chemicals.

Raman spectroscopy has been widely deployed over the past years. For example, surface-enhanced Raman spectroscopy (SERS) seems to be a promising method for water monitoring [14-22]. However, limitations still exist with respect to the detectability of Raman-inactive substances as well as the superposition of Raman signals by fluorescence, suggesting a combination of both detection methods to become more flexible in application.

Thus, in the future, a methodology will be required that enables detection and quantification of an increasing variety of pollutants in aquatic systems, often in very harsh environmental conditions as is typically found in wastewater treatment plants, oceans, lakes and other fluviatile systems. In our experiments, we show the detection ability of the Raman spectrometer for nitrates, some pharmaceuticals, and microplastics and their additives.

The newly developed deep-UV Raman/fluorescence spectroscope presented in this paper shows the potential to monitor a variety of substances without the need for sample preparation. The collected Raman spectra are analyzed with the use of a pre-trained convolutional neural network $(\mathrm{CNN})$, which has proven to be a reliable tool for the classification of spectral data [23]. This offers the ability for the automatic detection of chemicals in realtime, enabling reliable online measurements. In the following, the technical principles and first applications of the sensor system are described. The contribution of the paper offers the potential of Raman spectroscopy to detect substances down to a specific detection limit with several limitation factors, photo-degradation effects, spectral masking of solvents, and flow velocity in a flow cell. In this study, detection limits were estimated for nitrate/nitrite, selected pharmaceuticals, and the most widespread microplastic polymers as accuracy, precision, and device-specific sensitivity were quantified. In a companion paper, we extend the analysis to laser-induced fluorescence spectroscopy (LIF).

\section{Laser-Induced DUV Raman/Fluorescence Spectroscopy}

The environmental monitoring of chemical substances in aquatic systems is challenging since the water is a complex mixture of dissolved chemicals and suspended solids. In our current research, we investigate both Raman and fluorescence spectroscopy conducted with excitation in the deep UV below $250 \mathrm{~nm}$ since both methods are complementary and orthogonal and provide different but important information about materials within water. Deep UV excited Raman provides information about the molecular resonances of materials within the laser excitation volume, while fluorescence provides information about the overall electronic structure of the materials in the same laser excitation volume, as long as the excitation wavelength is sufficiently below the fluorescence features of interest to separate these two detection modes. Fluorescence background obscuration or interference of Raman emissions is a serious limitation for a wide range of analytes and background materials [24] when excitation occurs at wavelengths above $250 \mathrm{~nm}$, whether in the near UV, visible, or IR $[20,25,26]$. A unique property of fluorescence is that over $95 \%$ of all organic materials do not fluoresce below a wavelength of about $270 \mathrm{~nm}$, independent of 
excitation wavelength. As a result, if excitation occurs below about $250 \mathrm{~nm}$, there is a fluorescence-free spectral region in which weak Raman emissions can be detected [25]. Since the spectral regions of Raman and fluorescence do not overlap, a Raman-free spectral region exists for fluorescence detection also. This was first demonstrated by Asher [25] in general and by Ianoul et al. [27] in wastewaters. This spectral separation enables the Raman detection of species such as nitrates and nitrites, and other substances without the interference from organic materials found in all wastewaters. This spectral separation is important since fluorescence emissions are typically 100 thousand to 10 million times more efficient than Raman emissions so that a minute amount of fluorescent material within the view volume of the detector will obscure or alter the much weaker Raman emissions. Fluorescence detection on its own enables detection at much lower concentrations and provides the ability to also classify organic material by both phenyl-ring number and side chains, including microbial composite materials such as microbes or microplastics. Some materials do not fluoresce regardless of the excitation wavelength and are therefore only detectable with the Raman method. There are other advantages to deep UV excitation, including signal enhancement due to resonance and pre-resonance effects, which improves detection limits.

\section{Material and Methods}

Although the benefits of deep UV Raman spectroscopy have been known for many years [25], the lasers employed up until the present are very large, expensive, need large amounts of power, and water cooling. To overcome these physical and cost limitations, we utilize a compact, low-power, air-cooled $\mathrm{NeCu}$ transverse excited hollow cathode gas laser with an excitation wavelength of $\lambda=248.6 \mathrm{~nm}$ in the deep UV range from Photon Systems Inc. With this excitation wavelength, the Raman signals can be observed without fluorescence obscuration or interference of Raman spectrum [28-30]. An independent combination of both types of emission can improve the structural elucidation of unknown substances and show their substance-specific spectra without interference or obscuration $[30,31]$. All Raman measurements were performed using a commercially available Photon Systems' Deep UV Raman and Photoluminescence 200 (RPL 200; https:/ / photonsystems.com/products/lab-spectrometer-systems/raman-pl200/, accessed on 28 May 2021) instrument (Figure 1). The RPL 200 employs a $248.6 \mathrm{~nm} \mathrm{NeCu}$ laser, a $200 \mathrm{~mm}$ focal length Czerny-Turner spectrometer with computer-controlled 3600 and $300 \mathrm{~g} / \mathrm{mm}$ holographic grating, and a $2048 \times 128$ pixel, three-stage thermo-electrically cooled, back-thinned, back-illuminated CCD array detector. This fully self-contained portable instrument weighs about $12 \mathrm{~kg}$. The detector provides highly sensitive data (16 Bit CCD sensor resolution) with a very good spectral resolution of close to $251 / \mathrm{cm}$ to enable the detection of even small changes in the composition and or concentration of the dissolved substances. The resolution and LOD (limit of detection) are coupled via the slit size used: a larger slit leads to a better LOD but a lower resolution and vice versa. Since we were mostly interested in an improved LOD, we used a larger slit of $150 \mu \mathrm{m}$, which leads to a resolution of $251 / \mathrm{cm}$. The resolution can be increased to $81 / \mathrm{cm}$ by using a $50 \mu \mathrm{m}$ slit or even smaller to further enhance the resolution. The laser is fired in pulses with $40 \mu \mathrm{s}$ duration and average laser energy of $3.5 \mu \mathrm{J}$. 


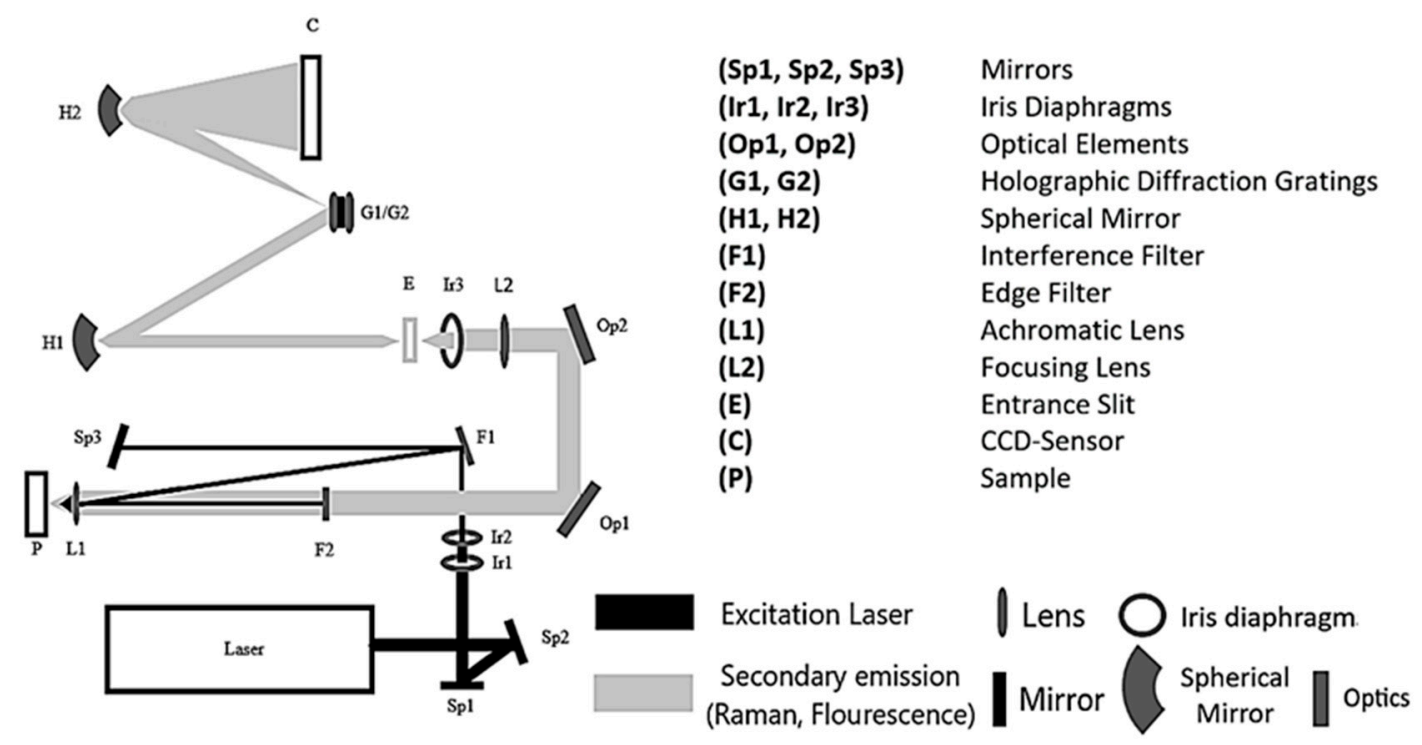

Figure 1. Optical set-up of the DUV Raman PL 200 from Photon Systems.

The monochromatic light of the $\mathrm{NeCu}$ laser is focused by two mirrors (Sp1, Sp2) to get through two iris diaphragms $(\mathrm{Ib} 1, \mathrm{Ib} 2)$, which regulate the aperture and the light intensity. The beam passes through an interference filter (F1), coated with a dielectric material, allowing the reflection of only the laser excitation wavelength of $\lambda=248.6 \mathrm{~nm}$. After that, the light is directed to a third mirror (Sp3) and then thrown back onto the interference filter (F1). The laser beam gets reflected at a different angle onto the achromatic objective (L1), which focuses the beam onto the measuring cuvette or the sample (P). The scattered Raman radiation passes through the achromatic objective (L1) and a lens (F2), which correspond to an edge filter. The Raman radiation is guided through the entrance slit (E) via two optical elements (Op1, Op2), a focusing lens (L2), and an iris diaphragm (Ib3) to finally hit the two spherical mirrors (H1, H2). The Raman radiation gets scattered onto one of the two holographic diffraction gratings $(\mathrm{G} 1, \mathrm{G} 2)$ to be detected by the $\mathrm{CCD}$ sensor $(\mathrm{C})$.

To prove the usability of the deep UV laser-induced Raman for environmental monitoring, we executed a number of laboratory tests to investigate influencing factors, such as the traceability of the substances, optical settings, agglomeration of insoluble substances, and flow velocity in a flow test. We focus on three groups of substances based on their environmental impact and their current scientific significance, namely nitrate/nitrite, selected pharmaceuticals, and microplastics.

The first step of the experimental methodology is the measurement of the pure substances (with 10 times repetition for accuracy studies) in a fused silica cuvette. This aims to specify the pure substance signal with the highest possible intensity, with an optimal sample distance to get a reference signal for recognition. In the second step, a dilution series from the substances was performed to reach the detection limit in the cuvette and to separate the signal of the fused silica cuvette from the substance signal. Consequently, in the case of substance solubility in water, the water spectrum has to be subtracted from the received signal, whereas the same procedure has to be performed when substances are only soluble in ethanol. In this setting, the influence of solvents was investigated regarding different solution concentrations on the course of the spectrum. In the third step, substance recognition in a flow cell with a sapphire lens was conducted, limited to water-soluble substances or microplastics. The objective of this set-up was to study the optical interferences of different glass types and to evaluate flow velocities and concentrations at which the detection of plastic particles was still possible. 


\subsection{Substances of Interest}

Nitrate/Nitrite, Pharmaceutical Micropollutions, Microplastic (MP)

Nitrate $\left(\mathrm{NO}_{3}\right)$ has strict threshold values $(<50 \mathrm{mg} / \mathrm{l})$, which must be maintained in most European countries' groundwaters (Nitrates Directive (91/676/EEC), Groundwater Directive, Water Framework Directive). Heavily loaded groundwater under farmland may reach up to $4000 \mathrm{mg} / 1$ of nitrate [32] due to over-fertilization. The EU groundwater guideline from 2006 (118/EG) demands monitoring the chemical status for assessing groundwater resources and quality. For detection of nitrate and nitrite ions, we used IC standard solutions by companies Merck and CarlRoth, with a concentration of $1000 \mathrm{mg} / \mathrm{l}$. The nitrate standard solution is certified and traceable to NIST (National Institute of Standard and Technology) standard reference materials, and it is manufactured in an ISO 17,034 accredited environment. The Nitrite Standard Solution is traceable to SRM from NIST $\mathrm{NaNO}_{2}$ in $\mathrm{H}_{2} \mathrm{O} 1000 \mathrm{mg} / 1 \mathrm{NO}_{2}$ Certipur $^{\circledR}$ (company Merck).

The concentrations of human pharmaceuticals in wastewater are usually well below critical thresholds, but adverse effects of pharmaceuticals were detected and proven [33]. The influence of antibiotics in wastewater on the development of bacterial resistance is also a crucial point. This topic is becoming increasingly important due to the partial degradability of the drugs in sewage treatment plants (Figure 2), incomplete absorption in the organism, and increasing prescription quantities [34].

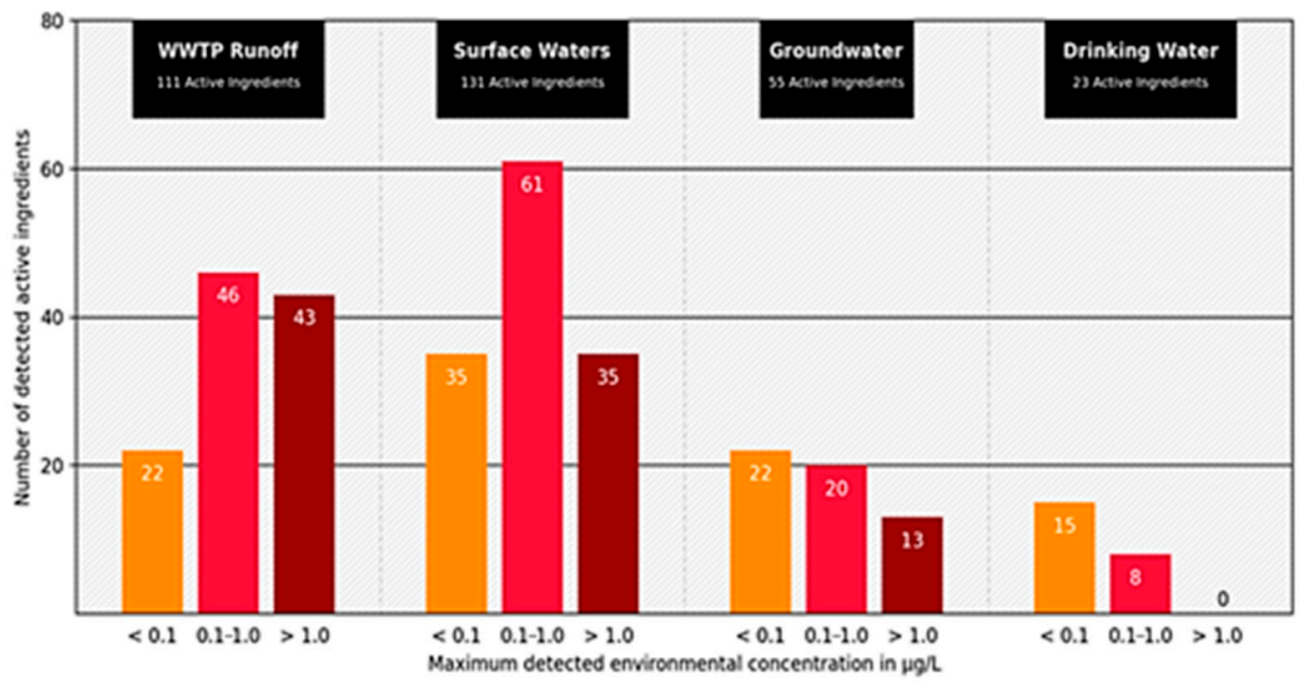

Figure 2. Number of active pharmaceutical ingredients measured in wastewater treatment plant effluents (111 active ingredients), surface (131 active ingredients), ground (55 active ingredients), and drinking water (23 active ingredients). Displayed according to concentration classes $(<0.1 \mu \mathrm{g} ; 0.1-1.0 \mu \mathrm{g} ;>1.0 \mu \mathrm{g})$ of the maximum measured concentration (modified according to [35] download available at https: / / www.umweltbundesamt.de/publikationen/zusammenstellung-vonmonitoringdaten-zu (accessed on 3 June 2021).

To date, the most common techniques for the determination of drugs in wastewater for sewage treatment plants are liquid chromatography or gas chromatography in combination with mass spectrometry, as they can detect substances down to the ng/L range [36].

In this study, acetaminophen (also sold under the brand paracetamol, purity $>99 \%$ ), metformin hydrochloride (treatment of diabetes, purity $>99 \%$ ), carbamazepine (anticonvulsants, treatment of epilepsy, purity $>98 \%$ ), hydrochlorothiazide (diuretic medication against high blood pressure, purity $>99 \%$ ), naproxen (analgesic, purity $>98 \%$ ), were tested. All pharmaceuticals were delivered by the company BioTrend (Cologne Germany), and the purity information is according to the manufacturer.

For this study, we utilize microplastic species, which are typically found in the aquatic environment, polyethylene (PE), polypropylene (PP), polyvinyl chloride (PVC), polysty- 
rol (PS), PC (polycarbonate), PES (polyester), PET (polyethylene terephthalate), PUR (polyurethane), PA (polyamide) and HDPE (high-density polyethylene) [37]. The recyclates were provided by the manufacturer Tetralog Kunststoffrecycling e.K, which produces plastic regrind, pellets, and granules on six lines, including two dedusting systems and one screening plant [38].

\subsection{Measurement, Preparation, and Experimental Strategy}

For the measurement of the above-mentioned substances, we used commercial high purity substances in order to avoid unintended additives or contaminations. The accuracy of the spectrometer is determined by acetonitrile (ACN). ACN is also used as the calibration standard, which is listed by the ASTM (American Society for Testing and Materials) as a calibration standard [24]. The wavenumbers $(1 / \mathrm{cm})$ of three Raman peaks, $13761 / \mathrm{cm}$, 2949 1/cm, 2999 1/cm, from the NIST (National Institute for Standards and Technology), are used as a reference for calibration (NIST). The precision of the Raman bands was assessed based on repeated (i.e., 10) measurements under identical settings (number of pulses; sample focal distance) and the resulting standard deviations s (Equation (1)).

$$
\mathrm{s}=\sqrt{\frac{\sum_{i=1}^{n}\left(x_{i}-\bar{x}\right)^{2}}{n-1}}
$$

With $n$ being the number of measurements and $\bar{x}$ the mean value of the measurements. All measurements were performed at room temperature.

In the first step, all pharmaceuticals were placed into the cuvette holder as an unprocessed powder. In the second step, they were brought into the solution, which was prepared with a scale and a pipette. To speed up the dissolution process, they were shaken and/or carefully warmed. Ethanol and water were used as solvents, depending on the drugs' dissolution properties.

Nitrate and nitrite were measured in aqueous solutions with the inevitable consequence that the spectrum of the water was always recorded. Correction of the unwanted water and cuvette signal was achieved by varying the distance from the laser lens to the cuvette (sample distance) to minimize its influence since a simple "subtract" would erase the whole signal. This correction was applied to all results.

The separation of the different kinds of plastic happens to be experience-based without any technical set-up. There was no sample preparation besides washing under running water, air drying, and sieving with a sieving machine (Retsch ${ }^{\mathrm{TM}}$, with sieve inserts with a mesh size of $0.063,0.125,0.25,0.5,1.0,2.0,4.0,8.0 \mathrm{~mm}$ ) to fractionate the particle size.

For the Raman static sample measurements, water samples were contained in fused silica cuvettes from the manufacturer Hellma ${ }^{\mathrm{TM}}$ or Starna Cell ${ }^{\mathrm{TM}}$. A cuvette containing the sample was located in front of the objective lens at the input/output of the RPL 200 instrument. Due to the fused silica of the cuvette also producing Raman emissions that can interfere with the water measurements, the $248.6 \mathrm{~nm}$ laser beam was focused nominally in the middle of the cuvette and not near the water/fused silica wall interface to maximize the signal from the water sample and minimize interference from the fused silica. The position of the laser focal point within the cuvette is important in minimizing this interference. Even with this minimization from the water spectral signal, the fused silica spectral background must be subtracted. For Raman flow measurements, the flow cell operates with a sapphire glass, which causes less optical interference than quartz glass.

The tests showed a signal optimum at a sample distance of $20.8 \mathrm{~mm}$ between the cuvette and the lens for the nitrate/nitrite measurements.

For thorough cleaning of the cuvette, the cuvette was placed in a bath of Hellmanex ${ }^{\mathrm{TM}}$ solution at approximately $40{ }^{\circ} \mathrm{C}$ for $30 \mathrm{~min}$. For most experiments with water-soluble substances, thoroughly rinsing the cuvette with distilled water was sufficient.

The measuring process was carried out with the software Spectrum Analyzer [39]. This software allows the operating of the spectrometer and the processing of the data. The 
measurement set-up requires cooling the camera down to $-35^{\circ} \mathrm{C}$ by an internal cooling system to reduce the natural noise caused by heat. Before measurements, the RPL 200 spectrometer instrument was calibrated. Acetonitrile $\left(\mathrm{C}_{2} \mathrm{H}_{3} \mathrm{~N}\right)$ was used for calibration at a sample distance of $f=10[\mathrm{~mm}]$ and a pulse count of $\mathrm{P}=20$ (Figure 3 ). Based on the position of the peaks and their distance to each other, the grid was optimally positioned.

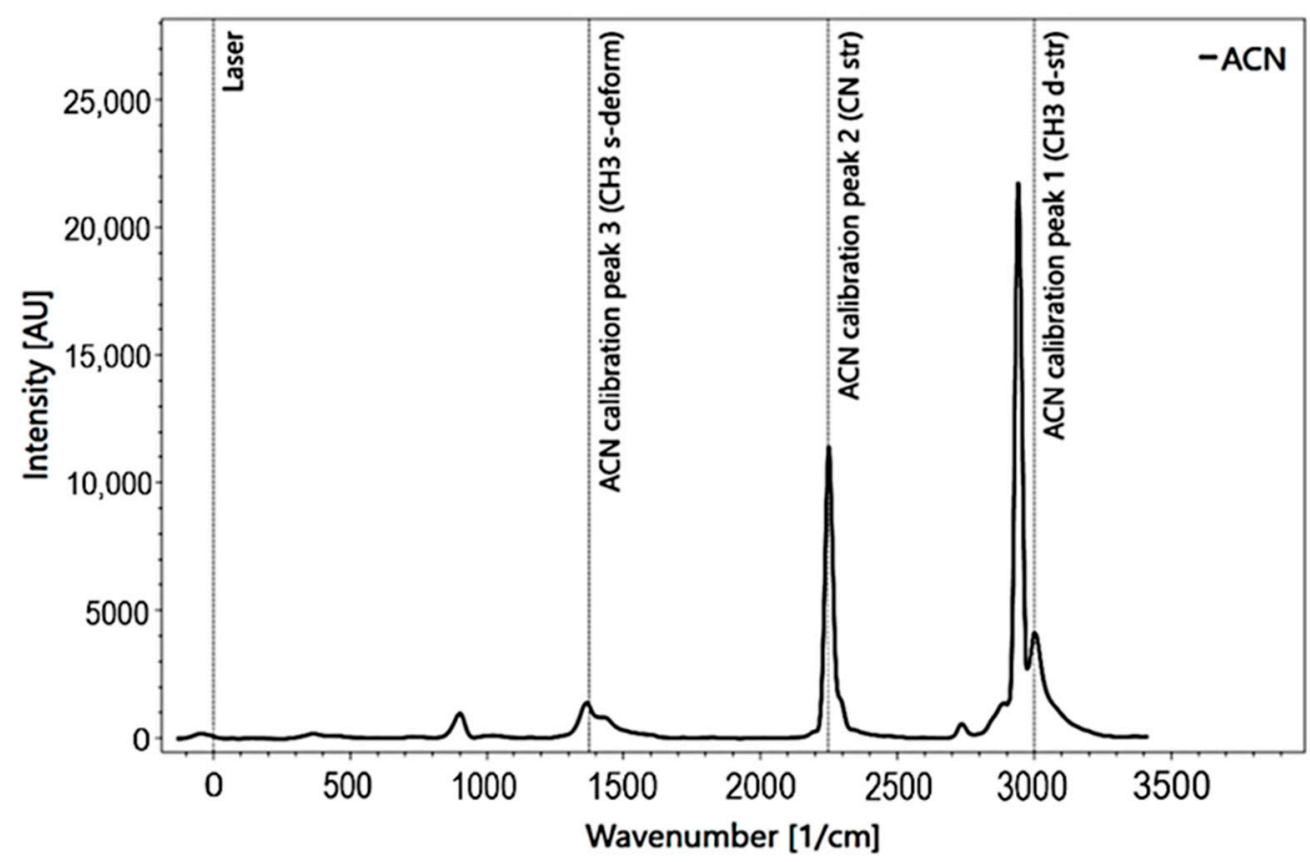

Figure 3. Acetonitrile calibration spectrum for Raman spectroscopy with added peak information.

To perform a Raman measurement, a grid with 3600 grid lines per millimeter was selected. For the analysis, the dark spectrum was subtracted from the raw spectrum (Figure 4).

In addition, the laser energy was recorded (Figure 4c), which enables the comparison of peak intensities of different spectra and an improved averaging of spectra. The measured laser energy was used to normalize all spectra to the same laser energy to compensate for a small deviation in the laser pulse energies. The average deviation is normally within a few percent.

The experimental procedure for nitrate/nitrite starts with the measurement of solid matter and then with solutions with concentrations of $0.5,5,10$, and $50 \mathrm{mg} / 1$. In the second step, different concentrations were measured in a flow cell using a sapphire glass lens instead of the fused silica cuvette to examine the influence of the different glass types. The pharmaceuticals, which were diluted in water or ethanol, were also first measured as a solid, pure powder. Repeated measurements were performed to identify possible photo-degradation effects. Subsequently, they were measured in solution at different concentrations (e.g., metformin hydrochloride $0.01,0.1,1,10 \mathrm{~g} / \mathrm{l}$ ) in a fused silica cuvette (for the evaluation of the detection limit, accuracy and influence of solvent). Finally, the experiments were performed in a flow cell set-up to consider the detection limit at a distinct flow velocity. Only the microplastic recyclates were not soluble. As a consequence, concentration calculations differ from the other substances. For the detection of the MP particles within the flow cell, the measurement time is not an independent variable. However, relations between flow velocity, particle size, and concentration exist [40]. Thus, the particle concentration was quantified using an experimental approximation for determining the 
number of particles $N_{\text {particles }}$ using $\rho_{\text {material }}$ the density of the polymer, per particle size class from the weighed mass of the sieve residues by the respective mesh size (Equation (2)):

$$
N_{\text {particle }}=\frac{\text { mass }_{\text {residues }}}{V_{\text {spherical }}} \cdot \rho_{\text {material }}
$$

The calculation of the volume $V_{\text {spherical }}$ is based on the assumption of an ideal, spherical particle. For the particle diameter, the averaged value of the two utilized sieve mesh sizes was used. With the calculated number of particles $N_{\text {particles }}$, a concentration (particles per volume) can be given. Furthermore, the mass concentration was calculated [40]. The concentration of particles $/ \mathrm{m}^{3}$ has become generally accepted [41,42], although it can also be given in $\mathrm{g} / \mathrm{cm}^{3}$ according to SI conformity. In this study, we utilized both units to ensure comparability with other studies.
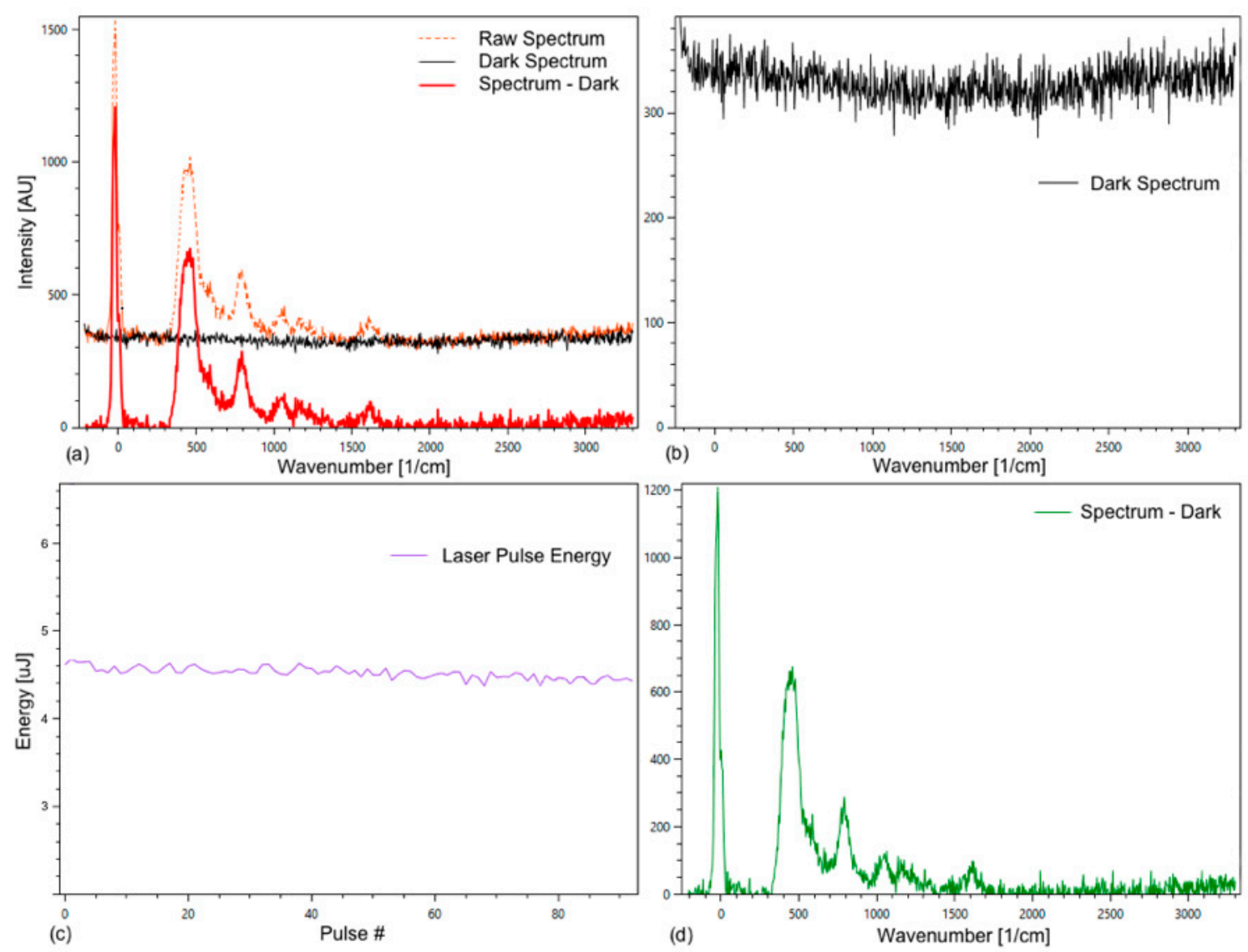

Figure 4. Tab Spectrum Debugger of the Spectrum Analyzer with raw, dark, and substance spectrum of an empty fused silica cuvette (a); (b) shows the dark spectrum; (c) energy plotted against the pulse count; (d) substance spectrum. The observed Raman spectrum is from the fused silica of the cuvette, which presumably is out of focus for the spectrometer, but strong enough to be visible.

For the MP detection, a rotary table was used to bypass the optical interference of the fused silica cuvette. Additionally, the height of the mapping table is adjustable, so the sample can be focused on the ideal substance-specific focal length of the optics. Furthermore, the measurement within the darkened mapping device leads to a better SNR ratio. By rotating the table, the influence of the particle surface and the photodegradation could be investigated. The MP particles were positioned in the focus of the laser by using a focus plate.

To test the identification of MP in real-time, different experiments using two sizes of flow cells were carried out. For the flow cell experiment, particles larger than $0.125 \mathrm{~mm}$ 
were measured to assess the influence of measuring time, flow velocity, particle size, concentration, and their relationships. For measurements in the small flow cell, a particle size of $\geq 2 \mathrm{~mm}$ and a mass concentration of $3.3 \times 10^{-6} \mathrm{~g} / \mathrm{ml}$ were used. The rationale for using a large particle size was to assess the impact of stationary and unsteady flow. The number of pulses was increased gradually.

The first Raman measurements in the flow cells were initially carried out without the use of the pump. The MP particles should flow through the experimental set-up only due to the hydraulic potential from the much higher reservoir. However, the implementation failed due to the regulation of the flow and the surface tension, which caused the MP particles to accumulate on the glass surface. After this, the measurements were carried out using the minimum flow rate of $4.99 \times 10^{-5}\left( \pm 1.70 \times 10^{-2}\right) \mathrm{m}^{3} / \mathrm{s}$ by the pump at a voltage of $4.0( \pm 0.1) \mathrm{V}$. The pre-study with different flow cell arrangements (Figure 5) should prove to control flow velocity and prevent the building of bubbles, as well as the sticking of the particles to the glass surface.

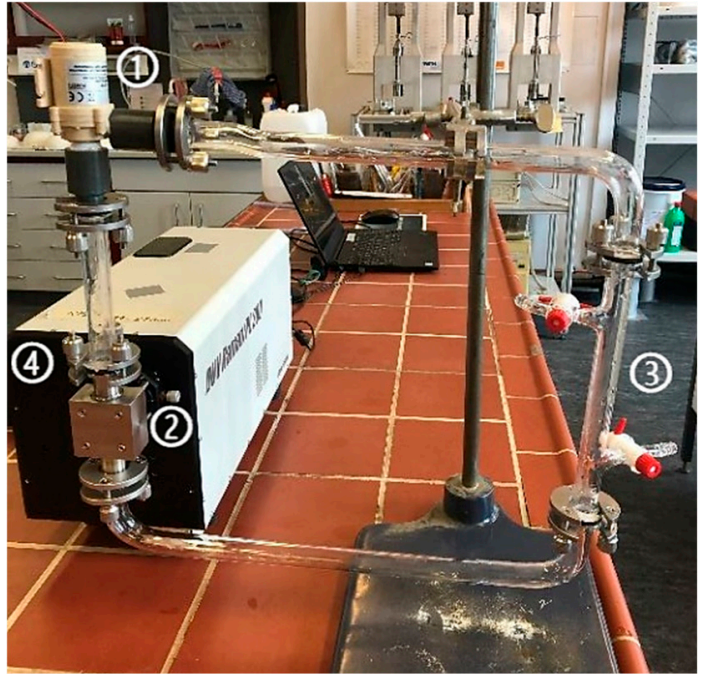

(a)

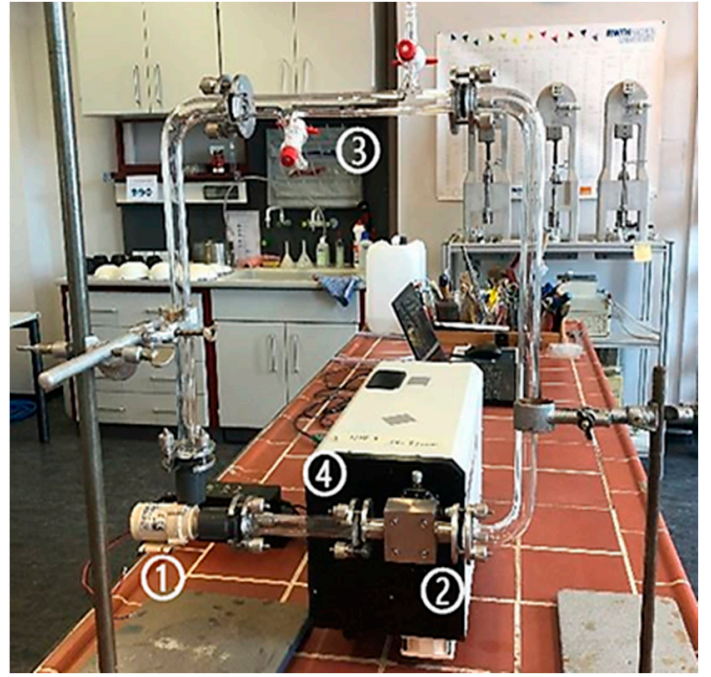

(b)

Figure 5. Flow cell construction in the vertical direction (a) and horizontal direction (b) with pumping, (1) pump, (2) flow cell, (3) inlet and outlet, (4) laser-spectrometer.

\section{Data Processing}

The spectrometer uses an internal measurement of each laser pulse energy and other system parameters to automatically compensate for any drift or deviation induced by such changes. This ensures high data quality and good traceability.

All measured spectra undergo dark, current, and baseline correction, smoothing (WhittakerHenderson Second-Order Smoothing) and normalization of the intensity scale. The normalization was based on the laser energy and was performed before averaging repeat measurements. The remaining trends, which could not be corrected by the baseline correction, are corrected by adjusting the offset. This processing step is especially necessary when negative intensities occur. In this study, the band position was determined by fitting Gaussian and Lorentz profiles to enable an assessment of the spectrometer accuracy. The fitting algorithm is based on the "Nonlinear Least Square fitting with Levenberg-Marquardt".

\section{Machine Learning}

The analysis of spectroscopic data is often challenging. This is due to the complex and diverse nature that recorded spectra exhibit. Chemical substances furthermore show anisotropies in their elastic scattering properties that depend on the orientation of the molecule relative to the laser. While the visual interpretation of recorded spectra is a commonly applied method, their automated classification has been a subject of research for 
several decades now [23]. Automated classification of spectra yields several advantages. For one, the inherent subjectivity that lies in the visual interpretation is eliminated and instead replaced by a reproducible, mathematical model. Furthermore, slight variations in spectra can be identified much more easily by a suitable algorithm, enabling an automatic classifier to make more nuanced distinctions than a human interpreter could. Finally, the algorithmic classification has the potential to obtain results rapidly and reliably even in continuous processes, making it much more suitable for full-time online monitoring than human interpretation.

Due to the high dimensionality and complex nature of commonly collected Raman spectra, linear models are unsuitable as classifiers in this context. For some time now, the application of artificial neural networks (ANN) to spectral classification problems has proven to be useful on spectra taken from complex mixtures of organic and inorganic compounds $[23,43,44]$. Especially the ANN variant 'convolutional neural network' (CNN) shows some significant advantages over other models, namely improved sensitivity, specificity, and the need for little to no data preparation [23]. CNNs are, therefore, very suitable models to automatically classify spectra taken from various types of samples. In this study, we utilize a novel CNN for data analysis developed by Liu et al. [45]. The authors have shown that the use of $\mathrm{CNN}$ can overcome most challenges of classical analysis methods, which need data preparation and signal processing before the actual analysis. Their proposed CNN improves commonly used approaches both in prediction accuracy (in our current CNN, about $97 \%$ prediction accuracy on the RRuff test data set) and classification speed. It also eliminates the need for most data preprocessing.

In the initial stage of software development, we reproduced the neural network with the same test data (RRuff minerals data library) and were able to reproduce the results from Liu et al. [45]. In the second stage, our own Raman data for different materials were added. The initial training on the RRuff database serves the purpose of adapting the $\mathrm{CNN}$ to Raman spectral data in general since the database provides the large amount of data needed for robust training. The spectra were randomly divided into training $(80 \%)$, validation $(10 \%)$ and test $(10 \%)$ datasets. The training step was done in 500 epochs. The data preprocessing was limited to resampling of the wavelength shifts to values from 1 to 4001, and the intensity values were rescaled to a value range from 0 to 1 . If less than 20 spectra were available for any given substance, the data were augmented using the conventional methods of adding noise, adding slight wavelength shifts, and mixing different spectra. The training was done on a NVIDIA RTX2080 Ti with 11 GB of Video RAM. The training with about 30,000 spectra took roughly one hour. The resulting CNN has a total of 2343 output classes consisting of minerals, microplastics, and pharmaceuticals. The classification of unknown spectra with the trained model takes only a few milliseconds on a standard CPU, which makes it suitable for real-time classification directly on the sensor itself.

In our software, we use the machine learning library TensorFlow from Google [46], which enables to load or update the machine learning model by simply deploying a new model file without the need for a software update. This offers additional flexibility to customize and adapt the analysis to new use cases and continuously improve the models.

\section{Results and Discussion}

\subsection{Results from Nitrates/Nitrites}

Solid matter Raman measurements with pure potassium $\left(\mathrm{KNO}_{3}\right)$ and sodium nitrate $\left(\mathrm{NaNO}_{3}\right)$ were performed. Several distinct signals are clearly visible in Figure 6 for both substances, with a significantly higher intensity of sodium nitrate compared to potassium. Sodium nitrate shows the maximum signal at a wavenumber of $10441 / \mathrm{cm}$. This signal was also used as a reference signal. 


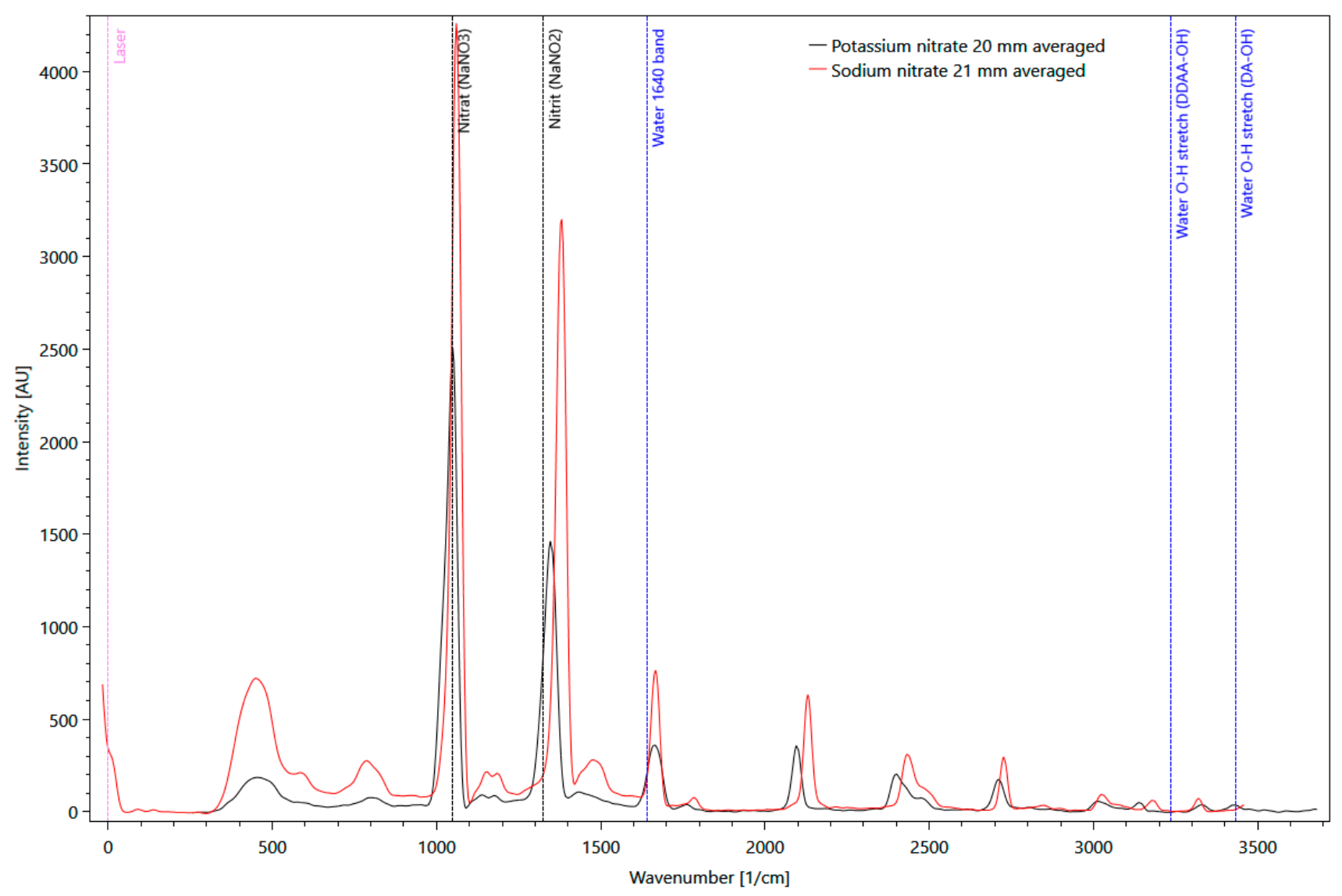

Figure 6. Comparison of pure potassium (black line) and sodium nitrate (red line) Raman spectra, measured as solid matter in a fused silica cuvette, with background information about molecular vibrations of $\mathrm{H}_{2} \mathrm{O}$ (blue dotted lines).

In a solution with a nitrate concentration of $50 \mathrm{mg} / \mathrm{l}$, the main signal at $10481 / \mathrm{cm}$, found in measurements of the solid matter, was also clearly visible (Figure 7). Other nitrate peaks could not be identified in the liquid sample due to the strong intensity of the water spectrum, which masks other nitrate peaks.

To overcome this limitation, the capability of the analysis software was extended for subtracting spectral water information obtained from a reference measurement from the measured spectrum.

The presentation of different nitrate concentrations derived from different intensities measured in a fused silica cuvette at the reference peak at 1048 1/cm is shown in Figure 8 in a detail enlargement of the spectrum.

The same procedure was applied for nitrite with different dilutions in the fused silica cuvette as well as in the flow cell.

In some cases, nitrate signal isolation was difficult due to an unfavorable signal-tonoise ratio or other interfering signals. The concentration was calculated by assuming a Lorentz curve for the reference signal. In addition, the parameters pulse count, laser power, and concentration of the reference measurement were used to obtain the most accurate results possible. After applying the mathematical adjustments to the $50 \mathrm{mg} / 1$ nitrite series, the mathematical average value can be adjusted from 57.21 to $51.86 \mathrm{mg} / 1$. In terms of sensitivity, differences in the $\mathrm{mg} / \mathrm{l}$ range can be recorded. However, the detection accuracy suggests that variations in the decimal range cannot be quantified.

The first result in a wastewater sample shows that the RPL 200 is able to identify nitrate, even in a solution with a wide variety of dissolved ingredients (Figure 9). 


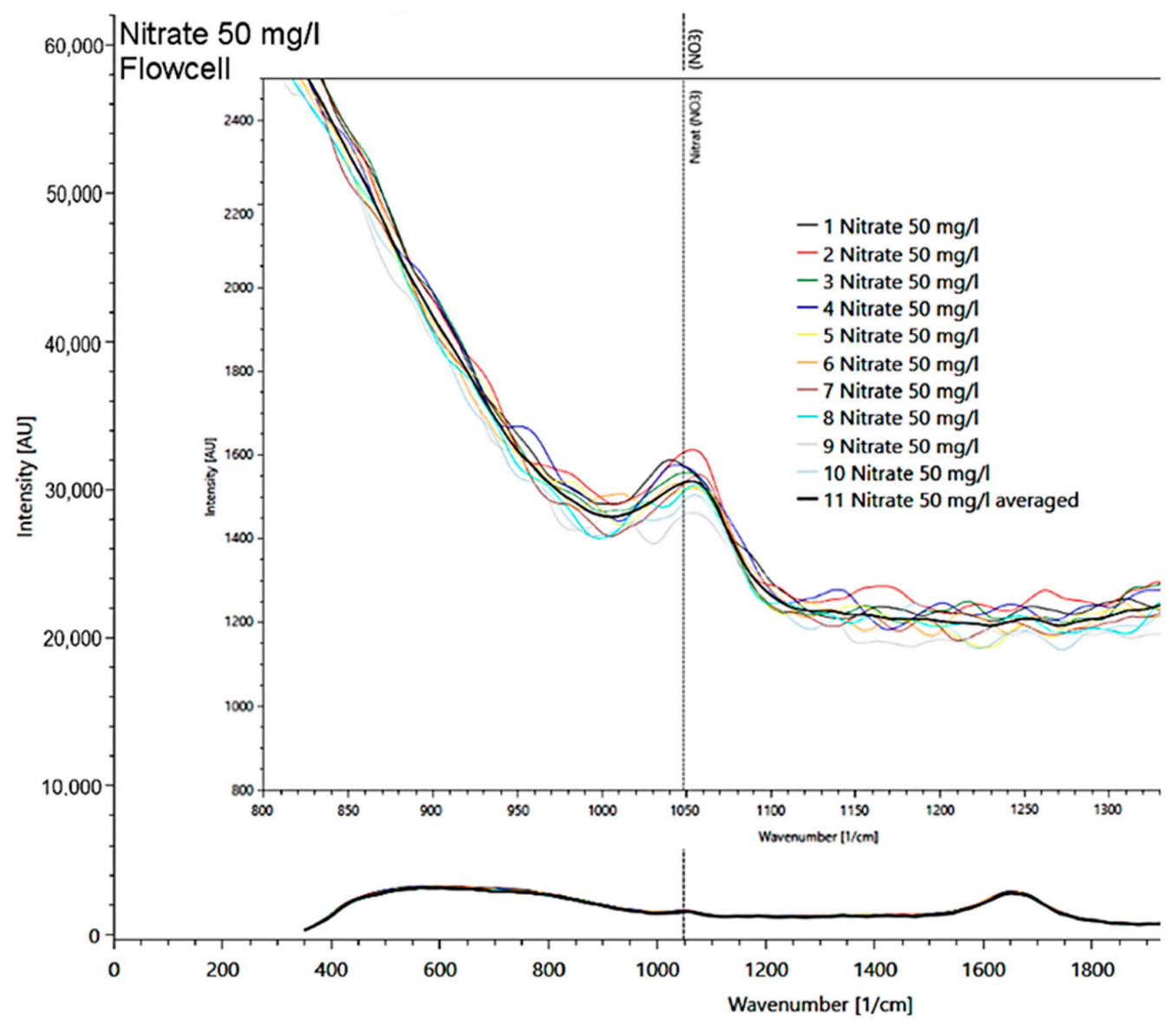

Figure 7. Presentation of the $50 \mathrm{mg} / 1$ nitrate spectrum measured in a flow cell with detail enlargement of the 10 measurement repetitions (multicolored lines; average as black line) at the reference signal at $10481 / \mathrm{cm}$.

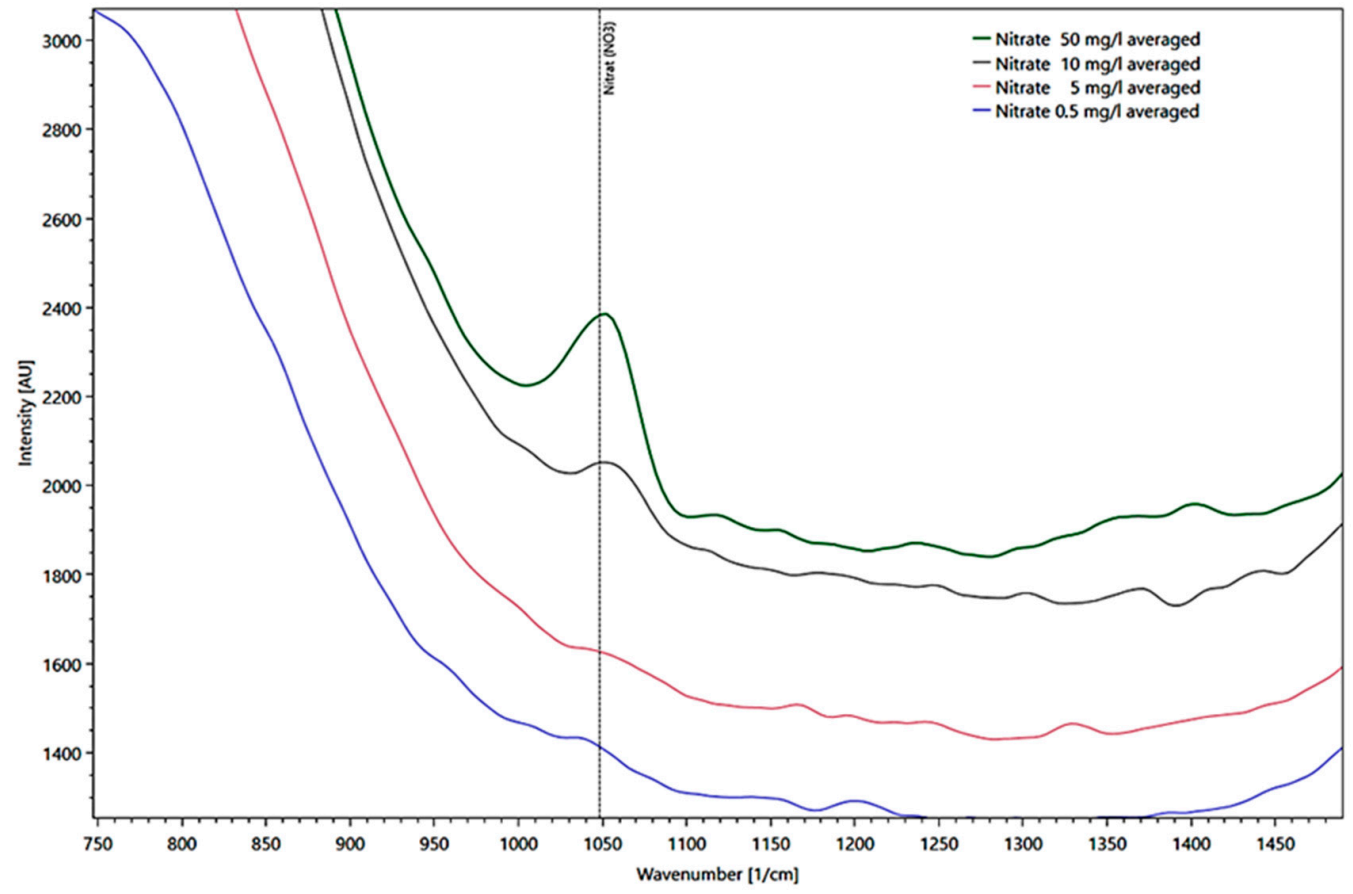

Figure 8. Presentation of different water peaks corrected for nitrate average concentrations from 50 (green line), 10 (black line), 5 (red line), to $0.5 \mathrm{mg} / 1$ (blue line) derived from their intensities as Raman spectra, measured in a fused silica cuvette. 


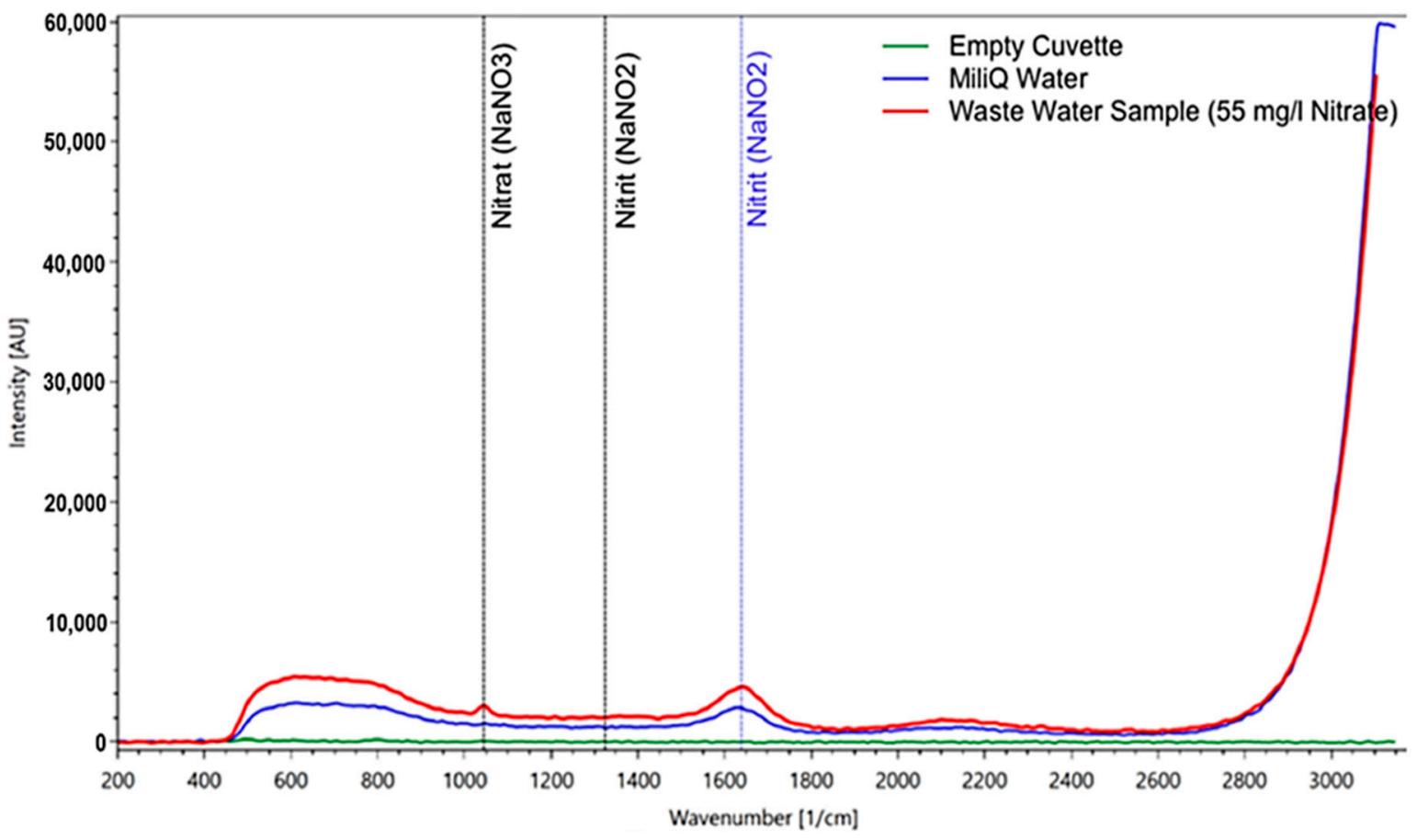

Figure 9. Measurement of a wastewater plant sample (after the biological cleaning stage) containing $55 \mathrm{mg} / 1 \mathrm{of} \mathrm{nitrate}$ according to the independent lab analysis. For comparison, the spectrum of pure water and of the empty cuvette are included. The nitrate peak is clearly visible and not obscured by any other substances in the sample.

\subsection{Results of the Pharmaceutical Substances}

For detecting pharmaceutical substances, which were partly dissolved in ethanol or water, it was inevitably necessary to subtract the ethanol/water spectrum from the spectrum of the dissolved substance according to its proportion in the solution, as illustrated in Figure 10. As long as a peak of the drug is visible in the spectrum, it can be detected. To determine the intensity of the peak, the spectrum of the solvent was subtracted from the spectrum of the solution.

The detection limit for the pharmaceuticals in solution was reached when the signalto-noise ratio was 3:1. The noise was empirically calculated using the number of slope changes at which the signal increases and subsequently decreases at a wavenumber without a continuous trend. The signal strength was then averaged and used as an approximation for the strength of the background noise. For powdered medication, an overall decrease in signal intensity was measured with increasing numbers of measurements. Thus, the spectral database developed in this study accounts for the measured intensity change over five measurements with 500 pulses.

The Raman spectrum of metformin hydrochloride shows increasing intensities from wavenumbers larger than $4001 / \mathrm{cm}$. The most intense spectral features were found at $2900-34001 / \mathrm{cm}$ and, more specifically, $33701 / \mathrm{cm}$ (largest intensity). The latter peak is likely associated with the asymmetric oscillation of the primary amine [47]. The peaks at 3084 and $31571 / \mathrm{cm}$ were related to the stretching of N-H [48]. For comparison with the literature data, the spectra measured in this study were corrected by adjusting a Rolling Baseline correction algorithm. 


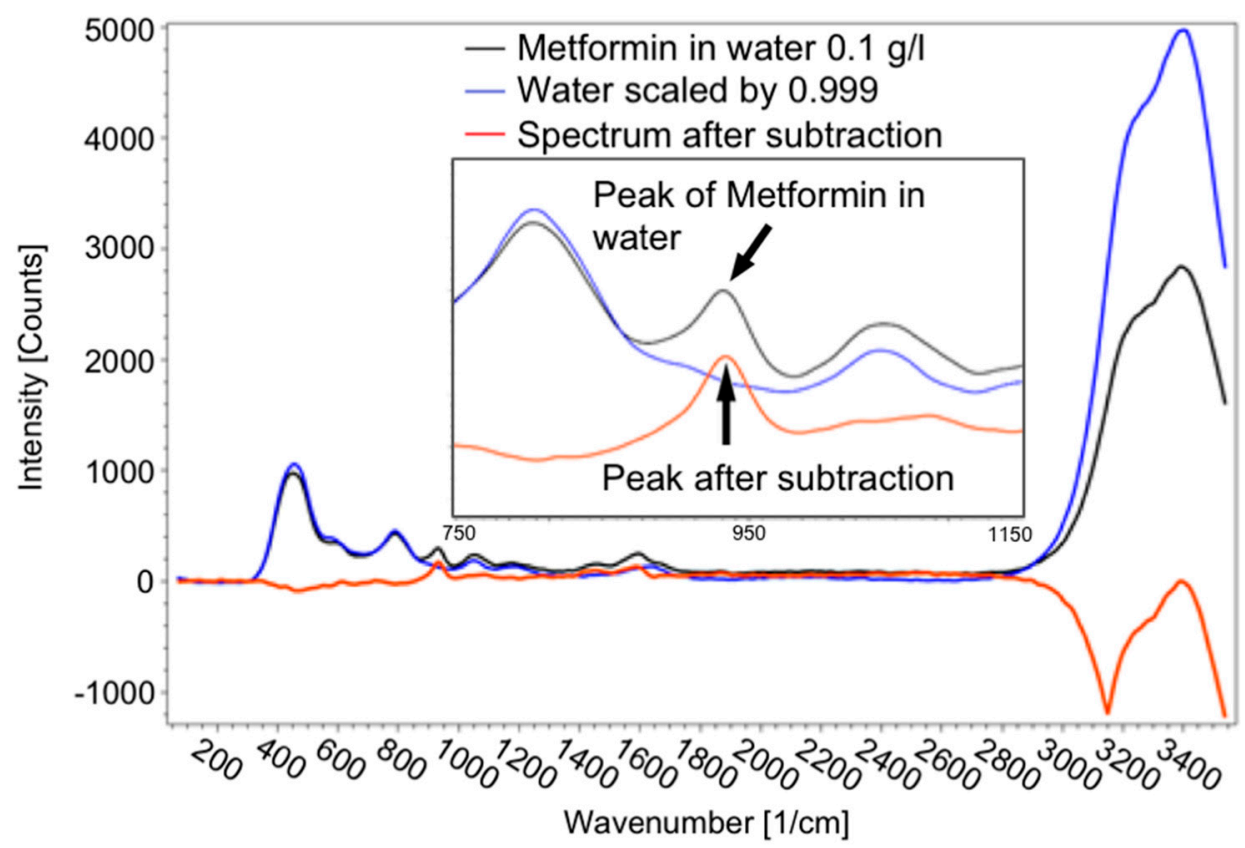

Figure 10. Spectrum of $0.1 \mathrm{~g}$ metformin hydrochloride in 11 water (black line), spectrum of scaled water (blue line) and spectrum after subtraction of the spectrum of water from the solution (red line), as well as a detailed view of the peak of metformin hydrochloride to determine the concentration.

Figure 11 shows the results of 10 consecutive measurements with metformin hydrochloride. The decreasing intensity trend with an increasing number of measurements can clearly be seen (Figure 11). The spectra were thus corrected, and all spectra were excited with the same laser energy.

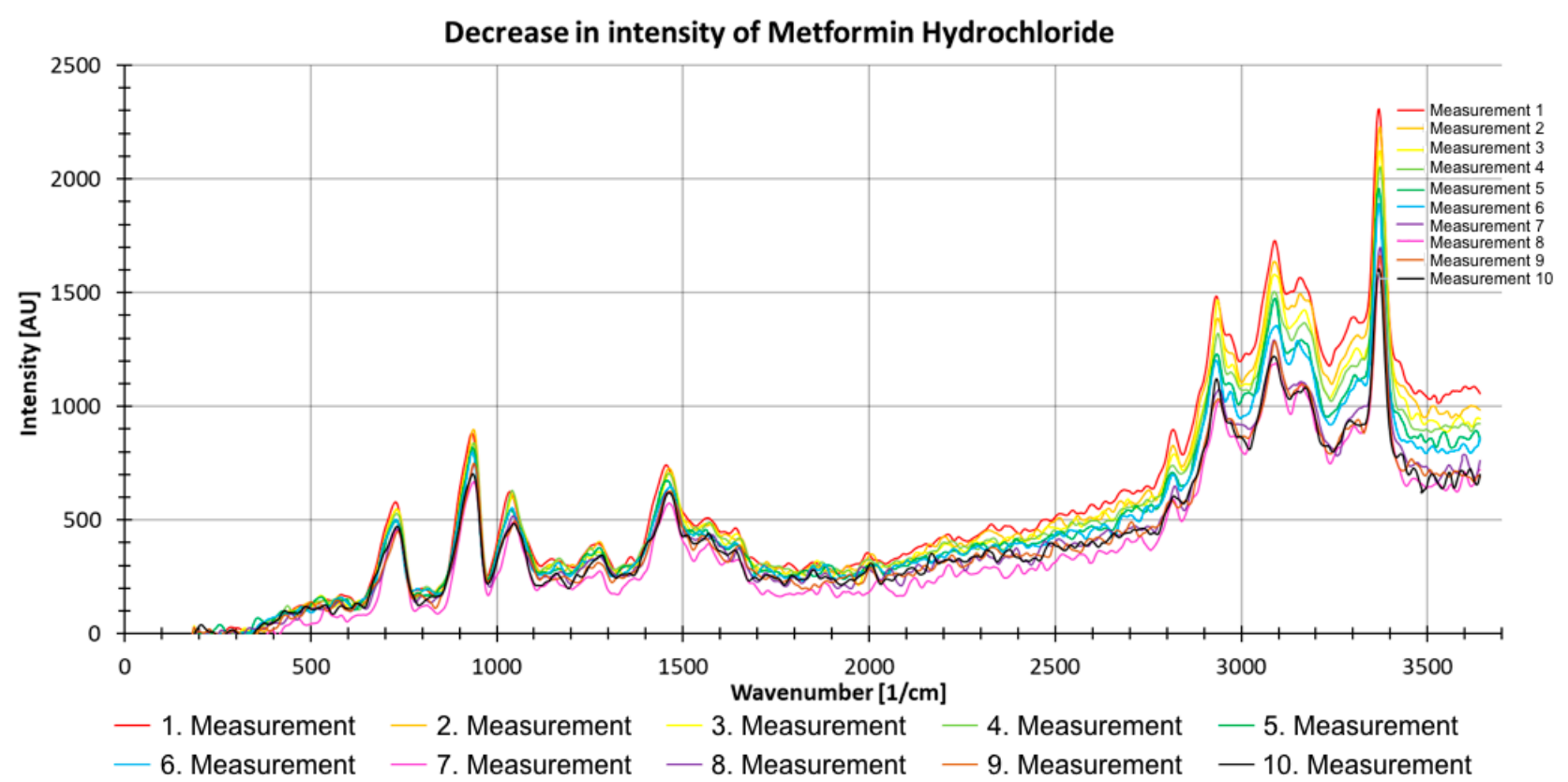

Figure 11. Decrease in intensity of 10 consecutive Raman measurements (with 500 pulses) of metformin hydrochloride as a powder.

For metformin, a non-linear decrease in intensities with decreasing concentrations was observed (Figure 12). In Figure 12, it is also visible that the water peak between 3000 
and $36001 / \mathrm{cm}$ increases with decreasing metformin hydrochloride concentrations, which suggests increasing visibility of the water peak with decreasing substance concentrations.

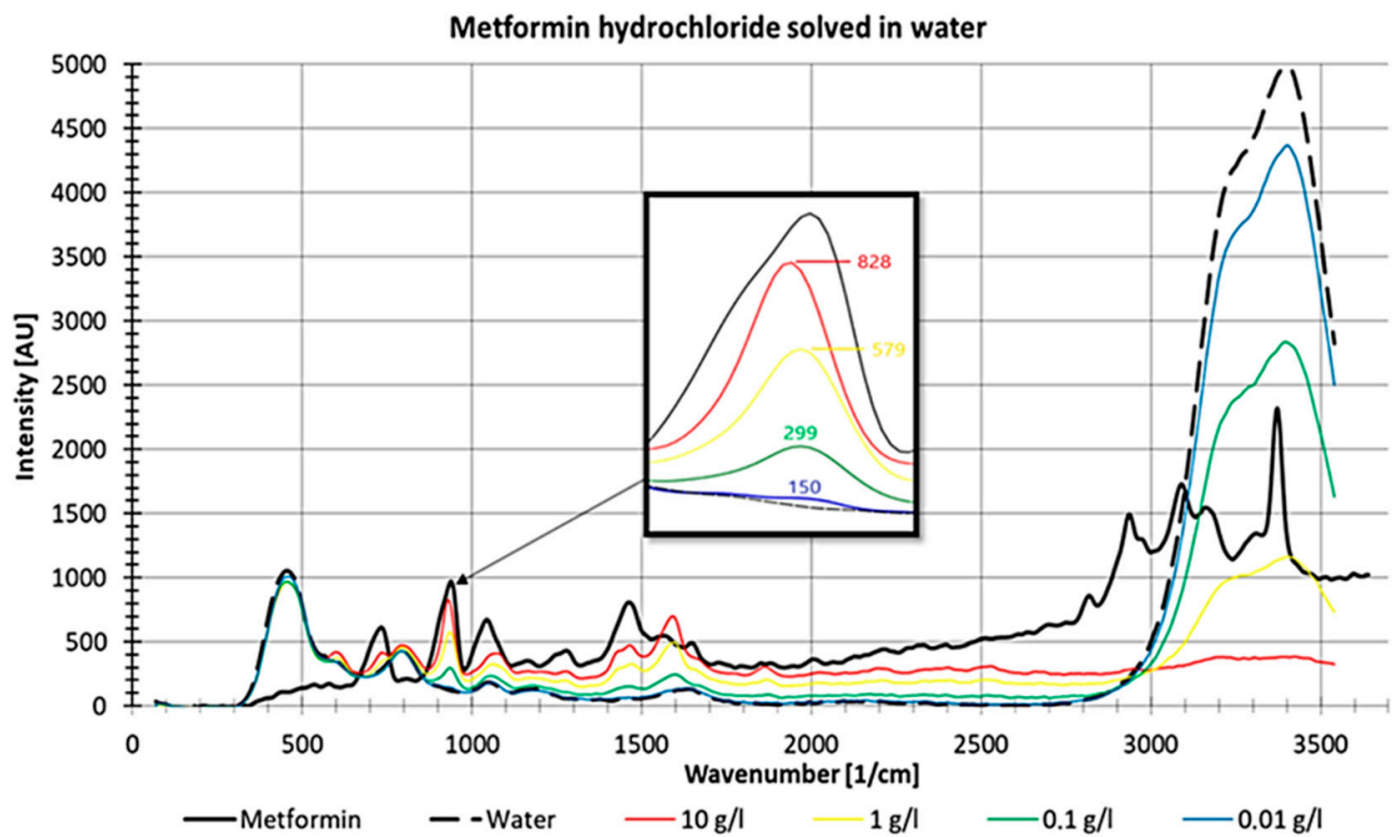

Figure 12. Raman measurements of pure metformin and different concentrations of metformin hydrochloride dissolved in water, measured in a fused silica cuvette with detail enlargement.

The different drugs show different decreasing trends with an increasing number of repeat measurements, possibly due to photodegradation. Naproxen, measured as a solid in powder form without cuvette, shows locally (i.e., individual wavenumbers) more than a 35\% decrease between two measurements. The peak at $13771 / \mathrm{cm}$ (is the deformation vibration of $\mathrm{O}-\mathrm{H}$, the symmetrical vibration of $\mathrm{C}=\mathrm{O}, \mathrm{CH}_{3}$, and $\mathrm{C}-\mathrm{CH}_{3}$ ) decreases substantially during repeat measurements $(37.2 \%)$, while the peak at $16191 / \mathrm{cm}$ (results from the asymmetric oscillation of $\mathrm{C}=\mathrm{O}$ and the carboxylic acid) decreases by only $9.0 \%$ (Figure 13).

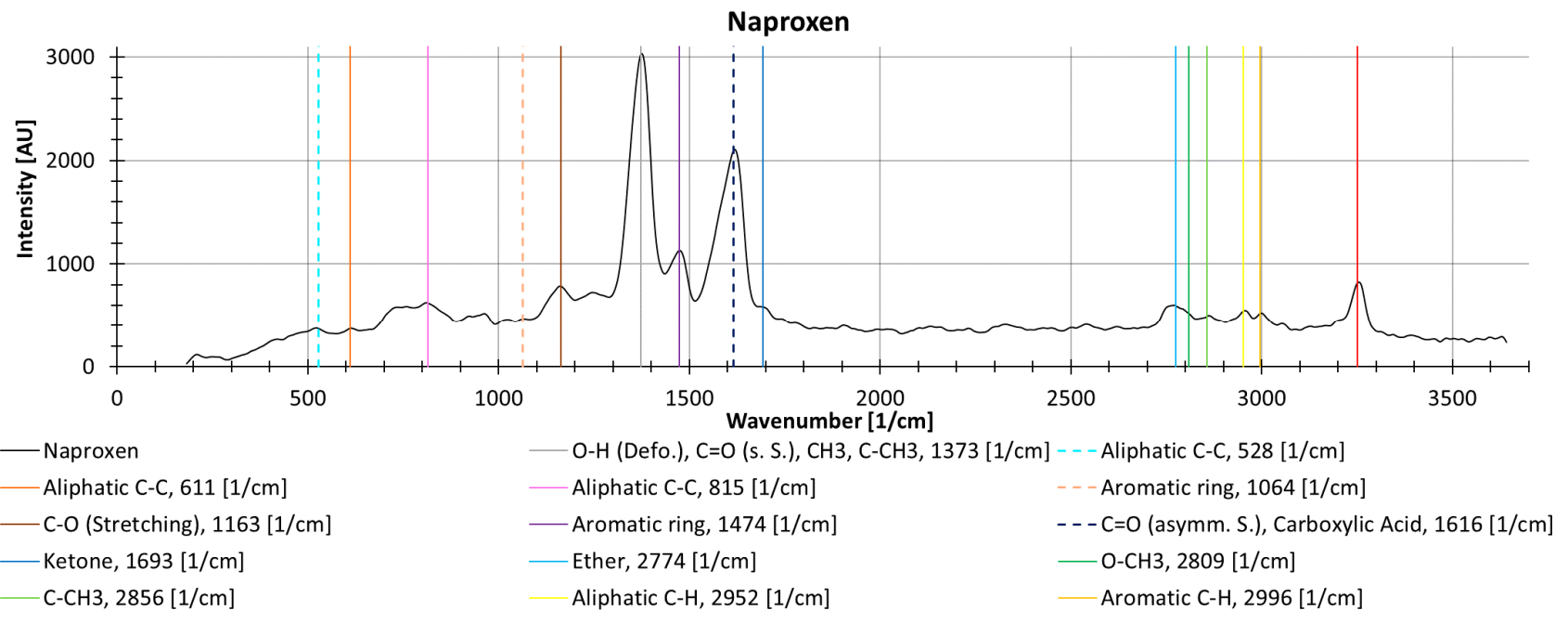

- O-H (Stretching), $3252[1 / \mathrm{cm}]$

Figure 13. Raman spectrum from naproxen as a solid powder (without cuvette), with information about molecular oscillation and peak identification from the KnowItAll software [47]. 
For determining naproxen concentrations dissolved in ethanol, the peak at $13731 / \mathrm{cm}$ was used because it showed the lowest spectral perturbation stemming from ethanol and the highest intensity of Naproxen (Figure 14). However, at this wavenumber, both spectra overlap slightly, which increases the complexity of determining the peak height at low concentrations.

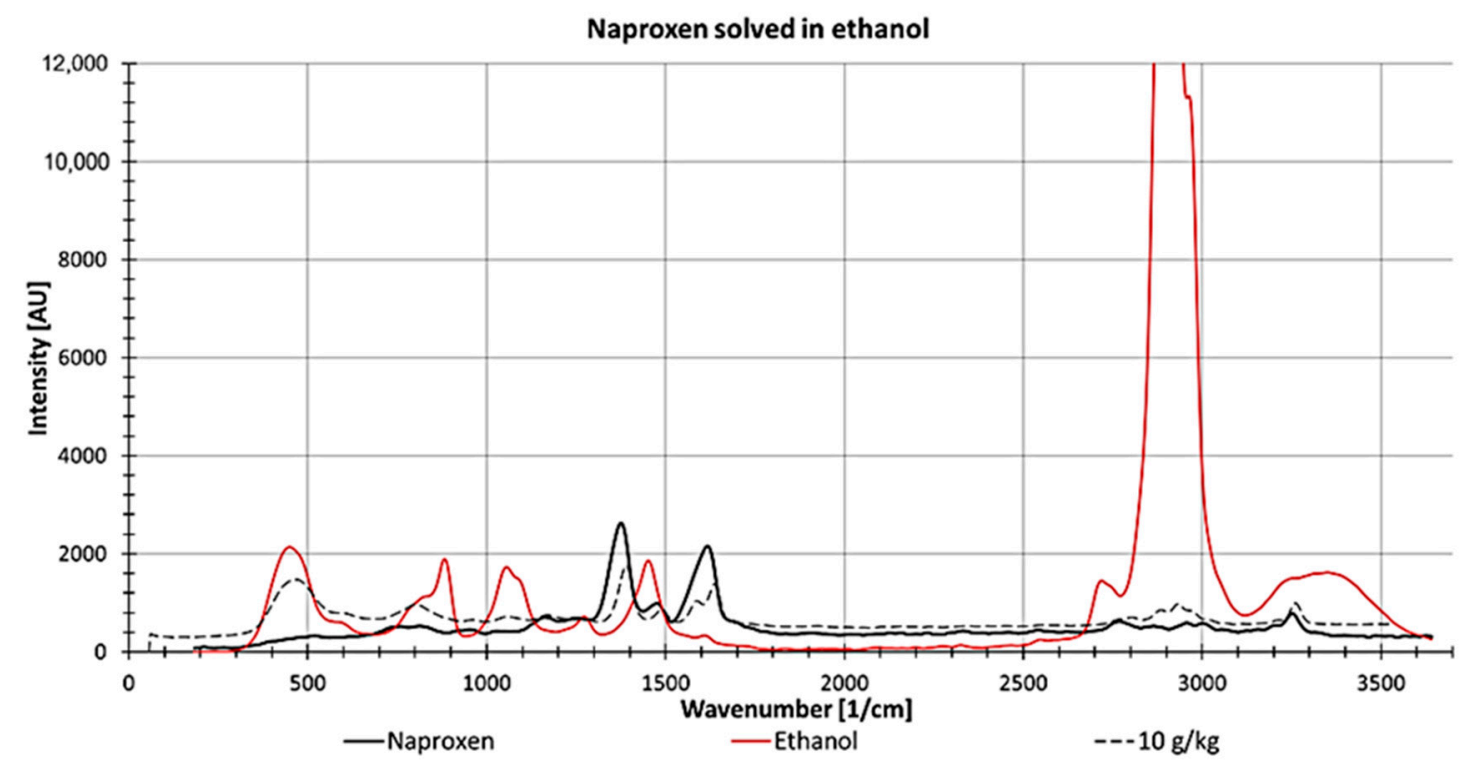

Figure 14. Raman spectrum from naproxen as a solid (black line) and ethanol (measured in a fused silica cuvette, red line) and $10 \mathrm{~g}$ naproxen dissolved in $1 \mathrm{~kg}$ ethanol (measured in a fused silica cuvette; dotted line).

Regarding the pharmaceuticals and the results of their Raman measurements, it is obvious that a detailed view on the interaction between the substances, their solvents, the measurement set-up (flow cell or cuvette), and possible degradation processes have to be taken into account. For some substances such as carbamazepine, an improved detection was observed at lower concentration $(<1 \mathrm{~g} / \mathrm{kg}$ ethanol). The data obtained for determining the calibration curve at low concentrations of carbamazepine were fitted with an exponential function $\left(y=0.0158 \mathrm{e}^{0.0326 \mathrm{x}}\right)$. The zero point of the equation and thus the theoretical detection limit is $0.0158 \mathrm{~g}$ carbamazepine per $1 \mathrm{~kg}$ ethanol. The coefficient of determination $\mathrm{R}^{2}$ was $96.7 \%$ (Figure 15) and thus significantly larger than for higher concentrations, which varied from 1 to $10 \mathrm{~g} / \mathrm{kg}\left(R^{2}=74.6 \%\right)$.

Metformin hydrochloride, which is soluble in water, was selected for the flow cell experiments. The major objectives of these experiments were (1) to evaluate the impact of the cuvette material (i.e., quartz versus sapphire) on the obtained spectra, and (2) to mimic conditions, which represent transport velocities in a wastewater treatment plant. Figure 16a shows metformin spectra obtained in the flow cell and Figure 16b in a fused silica cuvette. Up to a wavenumber of $8001 / \mathrm{cm}$, the influence of the different set-ups on the spectra is visible (compare the spectrum of fused silica cuvette in Figure 4d). For wavenumbers larger than $8001 / \mathrm{cm}$, the peaks of both spectra are the same. One major difference between the spectra of the two set-ups is the intensity of the water peaks (3000-3500 1/cm). Although the water peak in the fused quartz cuvette has approximately twice the intensity of the water peak obtained with the flow cell, the peaks of metformin hydrochloride were less affected, suggesting different sensitivities of the glasses. The maximum metformin hydrochloride intensity measured with the fused quartz cuvette was at a $23 \mathrm{~mm}$ sample distance. The intensity of water was at the maximum when the flow cell was directly adjacent to the spectrometer. At higher concentrations, the intensity of the peak for determining the concentration was larger in the flow cell than in the cuvette. At $0.1 \mathrm{~g} / 1$ the peak height in the flow cell was smaller. 


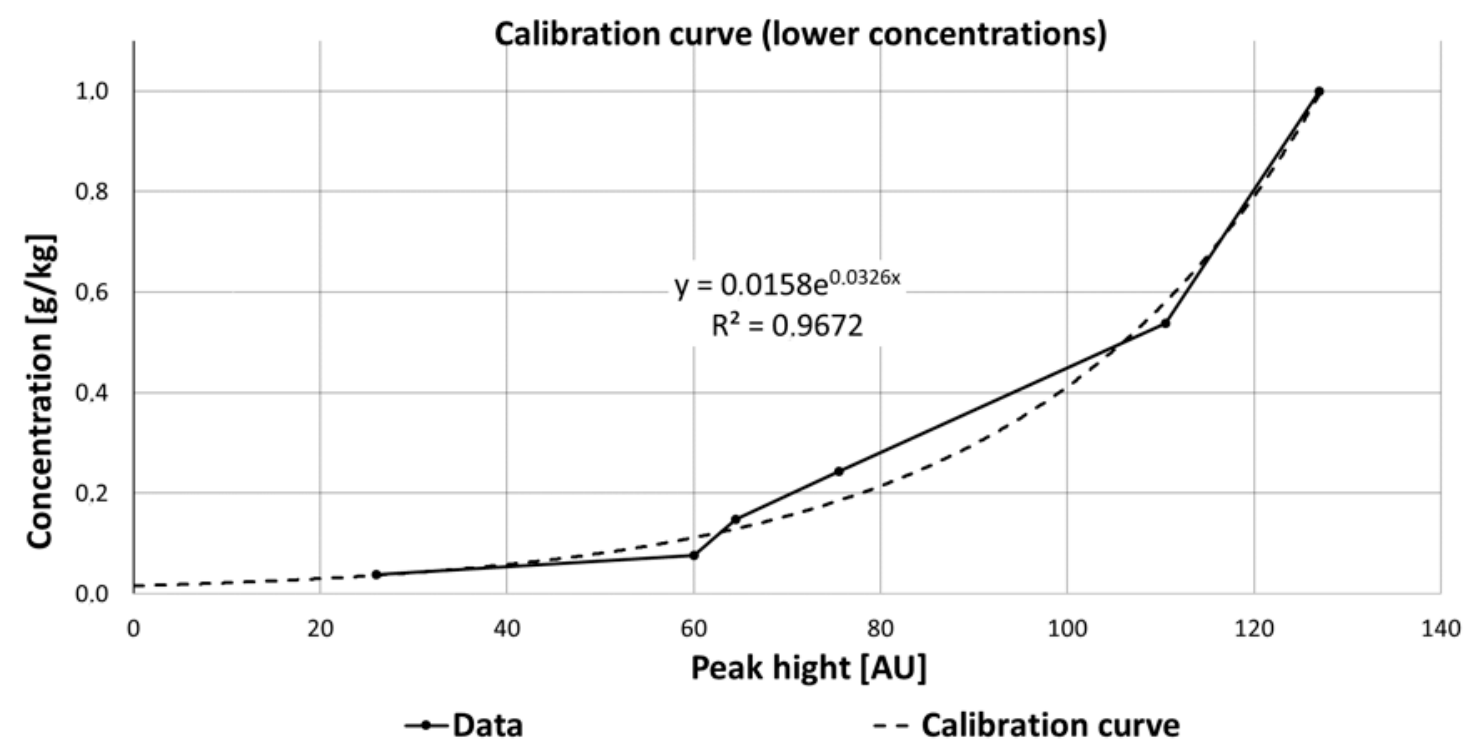

Figure 15. Calibration curve of carbamazepine at lower concentrations, fitted with an exponential function, which is described by the equation $\mathrm{y}=0.0158 \mathrm{e}^{0.0326 \mathrm{x}}$.

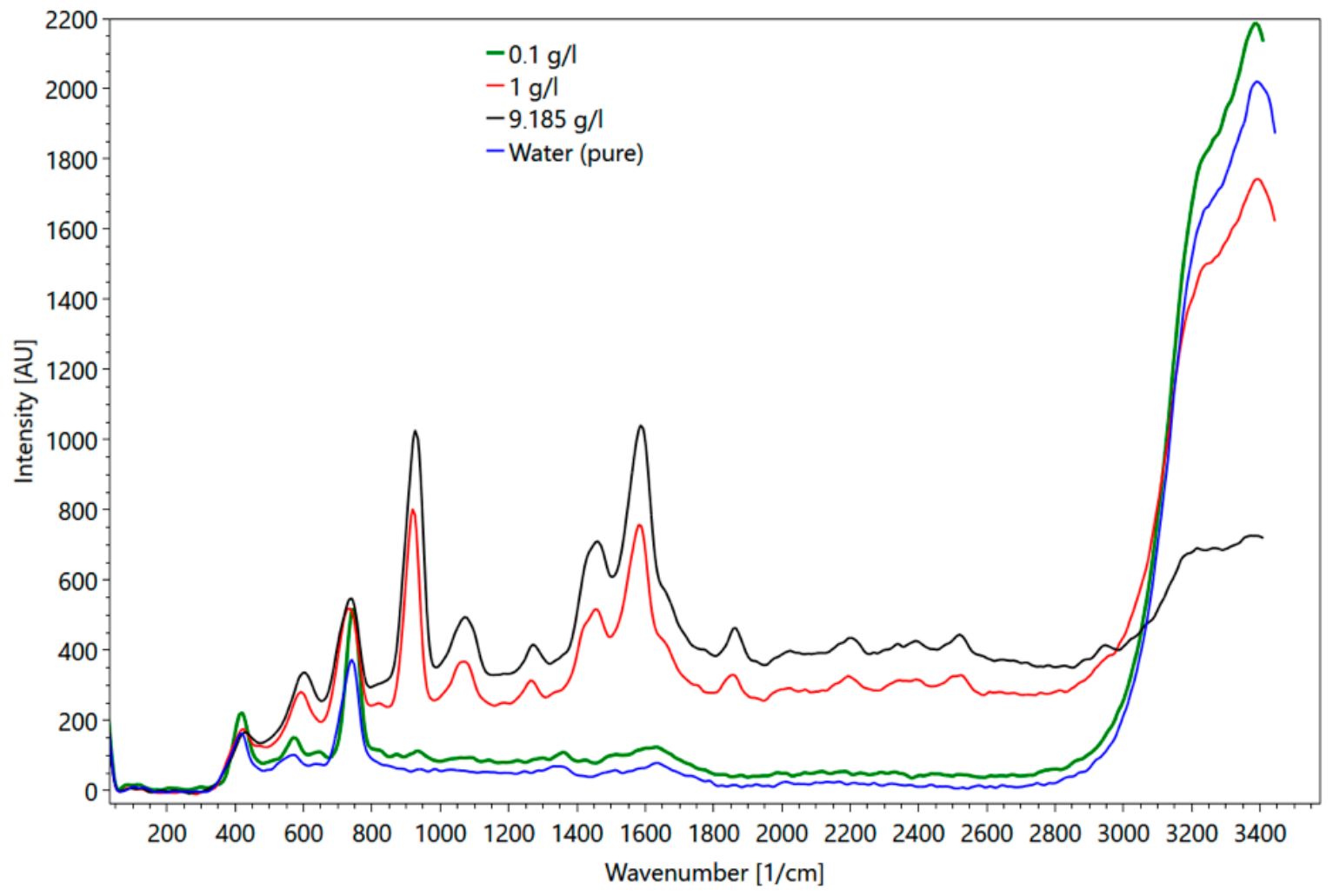

(a)

Figure 16. Cont. 


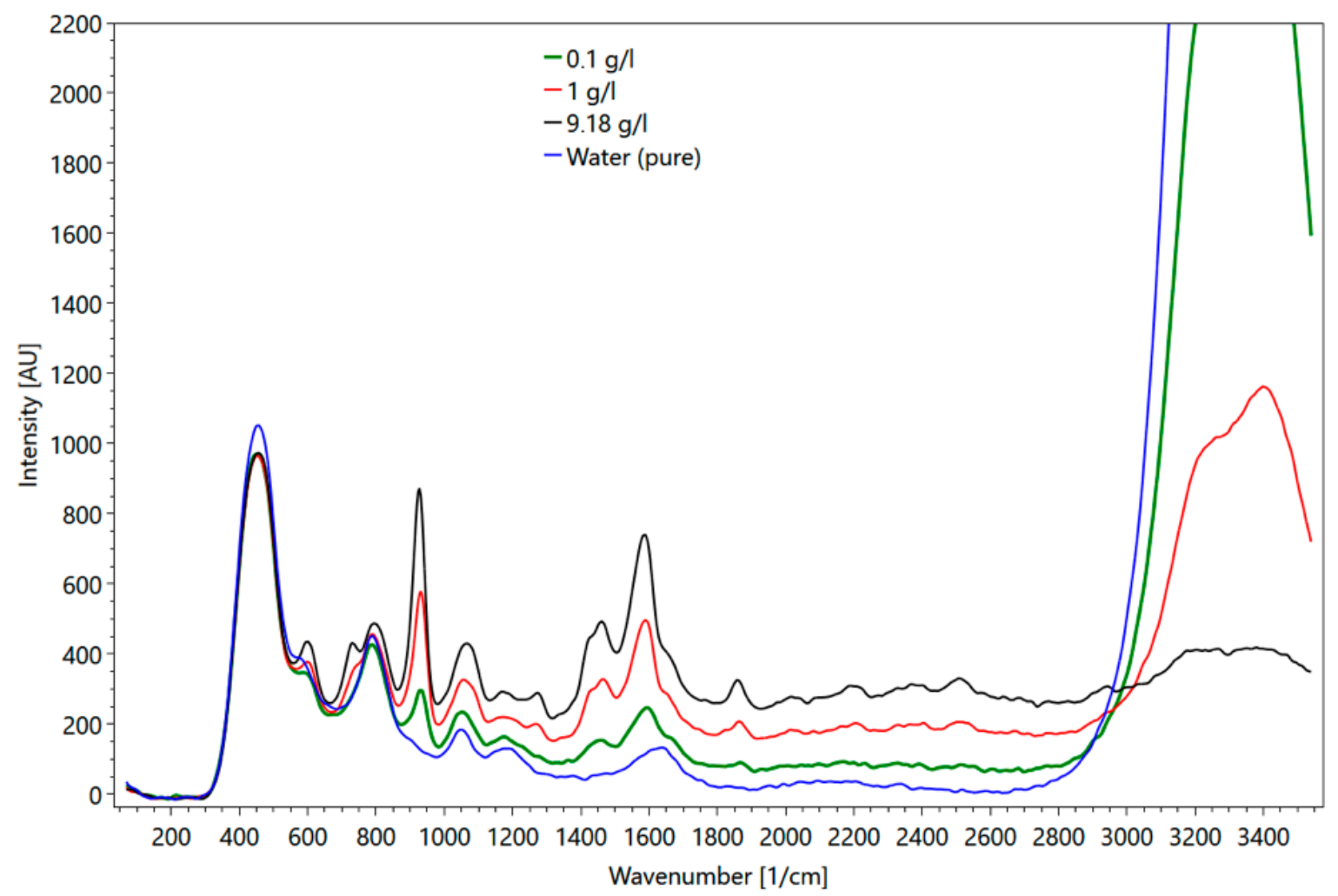

(b)

Figure 16. (a) Metformin hydrochloride measured in the flow cell with 0.1 (green line), 1 (red line), $9 \mathrm{~g} / 1$ (black line) and water (blue line); (b) metformin hydrochloride measured in the fused silica cuvette at 9 (black line), 1 (red line), $0.1 \mathrm{~g} / 1$ (green line) and water (blue line).

\subsection{Results of Microplastics (MP)}

To avoid the influence of inelastic scattering at the silica cuvette glass wall, the polymer recyclates were measured in a modified test arrangement. The analysis of the microplastics was performed using a rotary table (Figure 17a). The height of the rotary table can be adjusted to optimize the focal length in respect of the sample distance to the lens. Polymer recyclates were measured with at least 500 pulses (Figure 18a,b).

The obtained results suggest three factors that affect the data quality: (1) measurement time, (2) sample distance, and (3) the shape and position of the polymer particle. The particle surface led to strong fluctuations in the measurements of the same polymer type and pigmentation.

In addition to a spectral component analysis, the obtained spectra were compared with selected, published reference spectra (Figure 18a,b right) using the KnowItAll spectroscopy database [47]. This comparison showed an $80 \%$ agreement with published spectra. This might be related to an incomplete separation of the different microplastic species by the recyclate manufacturer.

In the large flow cell, measurements were obtained while the flow behavior was varied by adjusting the flow velocity. Under stationary conditions, particle detection required the particle to be in focus. Thus, limitations in detection are mainly associated with too fast flow rates (with the formation of bubbles) and a too-small laser cross-section. To improve the detection capabilities, the flow rate was, controlled and MP particles were used that showed Raman bands, which are unaffected by the water band. In addition, the concentration of particles was increased.

These adjustments allowed the detection of polymer HDPE MP with a particle size of $0.5 \mathrm{~mm}$ at a flow rate of $3.0 \times 10^{-1}\left( \pm 1 \times 10^{-2}\right) \mathrm{m} / \mathrm{s}$ and a mass concentration of 
$1.11 \times 10^{-3} \mathrm{~g} / \mathrm{ml}$ (i.e., a particle concentration of 1414.7 particles per $270 \mathrm{ml}$, Figure 19). Although the test results demonstrate the feasibility of MP detection in principle, the utilized concentrations do not represent natural conditions. Moreover, only particles hit by the laser could be detected, and thus, the measurements were subjected to a statistical probability.

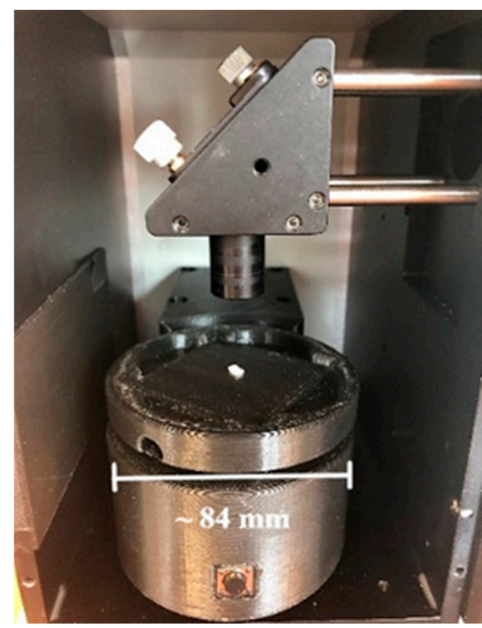

(a)

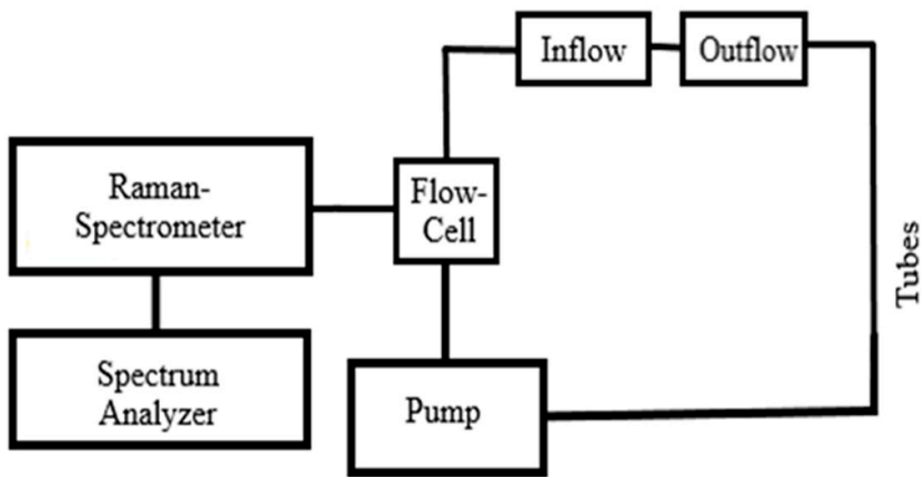

(b)

Figure 17. (a) Rotary table for the detection of MP particles, (b) scheme of the experimental setting for real-time detection of MP in streaming water under different flow behavior.
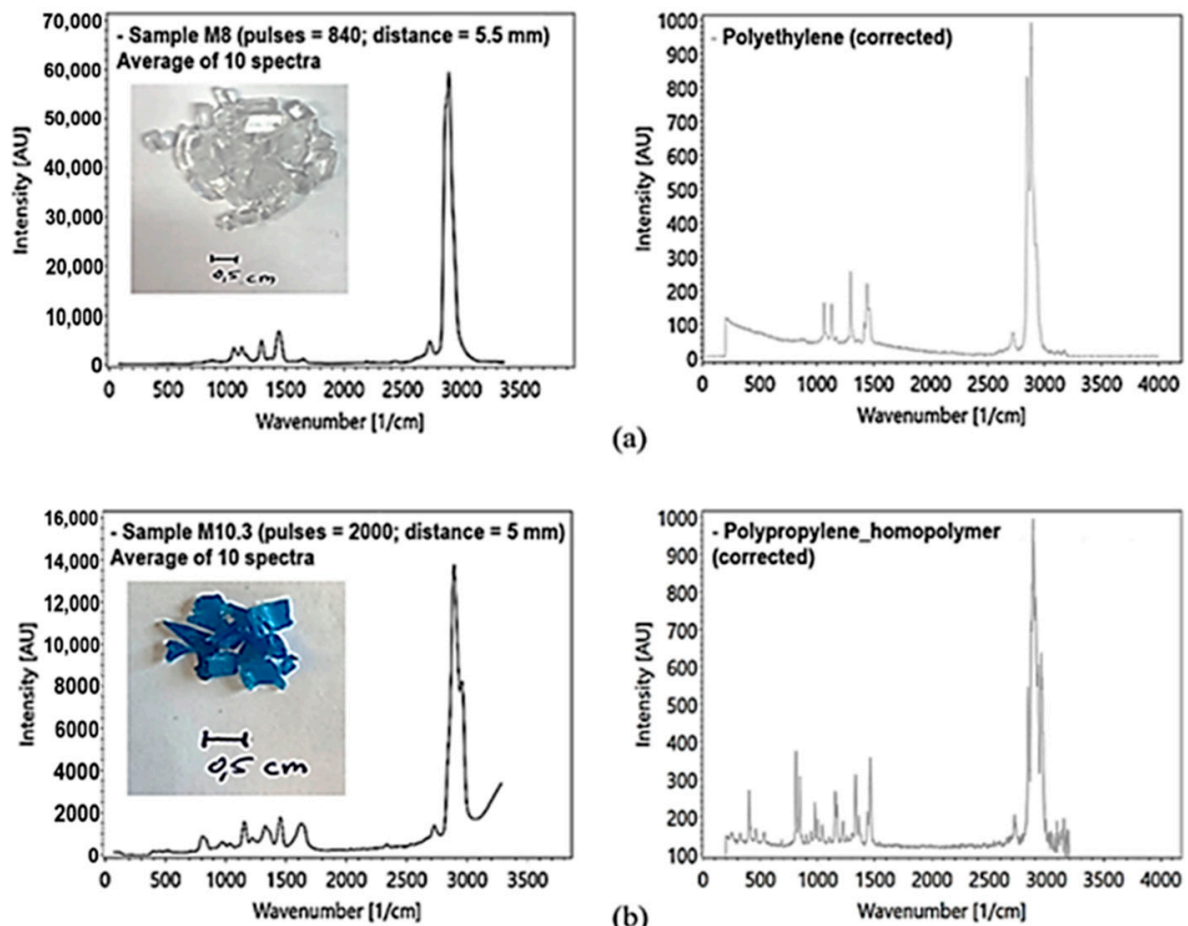

(a)

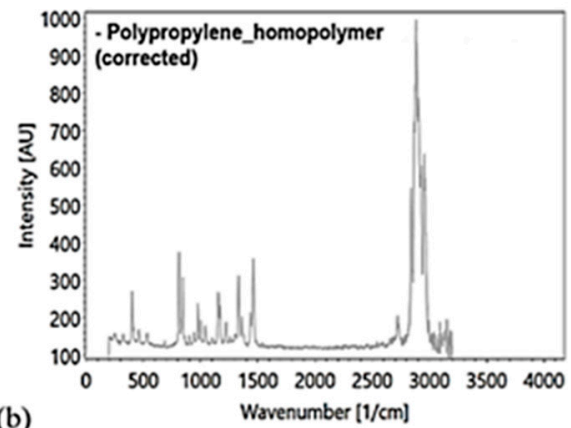

Figure 18. (a) PE sample, transparent, Raman measured with the rotary table, averaging of 10 spectra ((a) left) with reference spectra of PE ((a) right) by [39]; (b) PP sample, blue, Raman measured with the rotary table, averaging of 10 spectra ((b) left) with reference spectrum ((b) right) by [39]. 


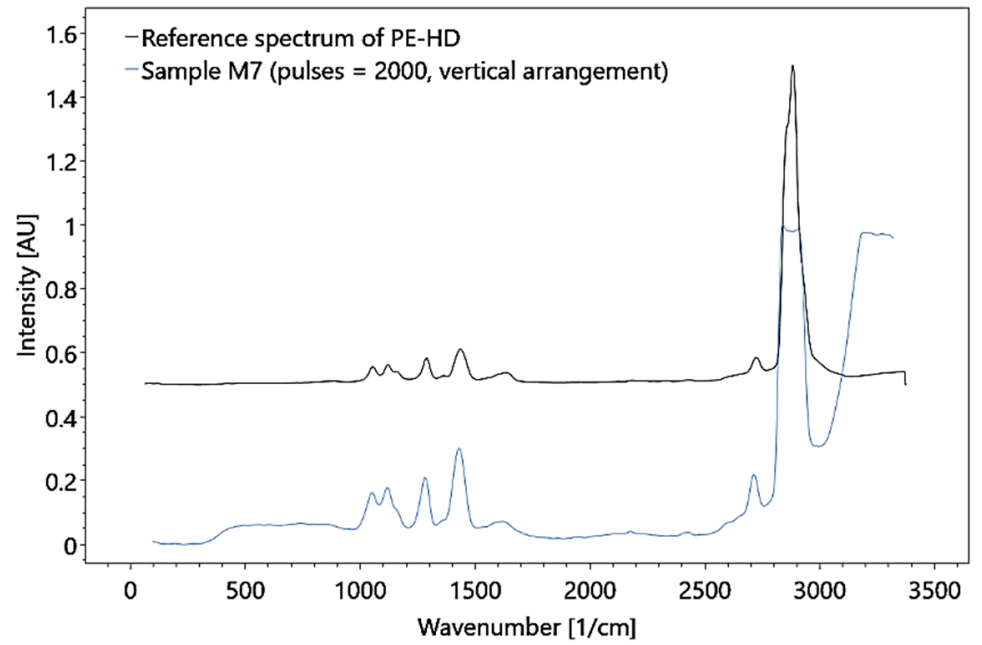

(a)

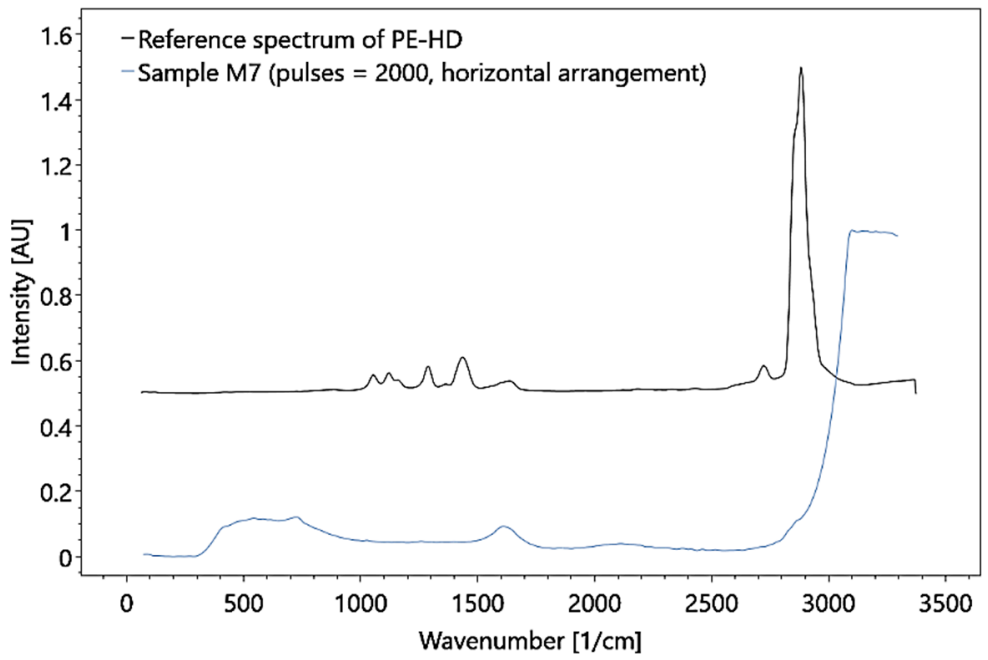

(b)

Figure 19. Raman analysis of the HDPE sample in the large flow cell, under (a) vertical and (b) horizontal arrangement, with a particle concentration of 1414.7 particles per $270 \mathrm{ml}$ and $0.5 \mathrm{~mm}$ for the particle size.

\section{Conclusions and Outlook}

We tested the feasibility of using deep UV Raman spectroscopy in combination with artificial intelligence software for environmental monitoring. In this initial study, we selected substances based on their environmental impact (i.e., nitrate, pharmaceuticals, microplastics).

Initial results gained from a series of experiments with a variety of substances and a bundle of different experimental set-ups measured suggest that the reliability for detecting and monitoring the selected substances in water with Raman spectroscopy suffers from a series of limitations. A major limitation is the low sensitivity (i.e., the detection of lower concentrations in the $\mu \mathrm{g}$ or ng scale). MP measurements are limited by the probability of particles in the focal point of the laser at low concentrations or at high flow velocity.

Although the CNN performs better for data classification than more classical approaches such as Pearson correlation or other mathematical algorithms of pure substances with high signal-to-noise ratios, our first measurements of dissolved pharmaceuticals show that the main challenge will be to get a useable signal at all for the very low concentrations of pharmaceuticals in actual wastewater or groundwater samples. Therefore, more measurements are needed to assess the performance and limits of the $\mathrm{CNN}$ when provided with 
very low signal-to-noise ratio data. However, current developments focus on the fusion of Raman and fluorescence measurement to combine the high sensitivity of fluorescence measurement with the high specificity of Raman.

First results on wastewater samples show that the RPL 200 is able to detect nitrate ions even in the presence of a wide variety of other ingredients.

The additional data gained from the sensor fusion approach may help for better training of the machine learning and to make predictions and classification results more robust by allowing cross-validation with independent sensor data in real-time.

Author Contributions: Conceptualization, C.P., F.A.; methodology, S.B., W.H., R.R., M.R., and R.B.; software, S.B., Q.N., R.R., and M.R.; validation, N.H., S.S., and L.G.; formal analysis, S.B., R.B.; investigation, C.P., N.H., S.S., A.F., and L.G.; resources, C.P., S.B.; data curation, S.B, A.F.; writingoriginal draft preparation, C.P., K.W., W.H., S.B., N.H., S.S., and L.G.; writing-review and editing, C.P., W.H., K.W., A.F., and F.A.; visualization, N.H., S.S., and L.G.; supervision, F.A., H.S.; project administration, F.A., C.P. All authors have read and agreed to the published version of the manuscript.

Funding: This research received no external funding.

Institutional Review Board Statement: Not applicable.

Informed Consent Statement: Not applicable.

Data Availability Statement: Data sharing not applicable.

Conflicts of Interest: The authors declare no conflict of interest.

\section{References}

1. Goldsmith, A.B. Monitoring for Conservation and Ecology, 1st ed.; Springer: Dordrecht, The Netherlands, 1991.

2. Ryan, P.G.; Moore, C.J.; van Franeker, J.A.; Moloney, C.L. Monitoring marine plastics-Will we know if we are making a difference? S. Afr. J. Sci. 2020, 116, 1-9. [CrossRef]

3. Gomes, P.I.A.; Wai, O.W.H. Investigation of Long-Term River Water Quality Trends in Hong Kong to Identify Role of Urbanization, Seasons and Pollution Sources. Water Air Soil Pollut. 2020, 231, 137. [CrossRef]

4. Pivetta, R.C.; Rodrigues-Silva, C.; Ribeiro, A.R.; Rath, S. Tracking the occurrence of psychotropic pharmaceuticals in Brazilian wastewater treatment plants and surface water, with assessment of environmental risks. Sci. Total Environ. 2020, $727,138661$. [CrossRef] [PubMed]

5. Palmer, J.A.; Law, J.; Soupir, M.L. Spatial and temporal distribution of E. coli contamination on three inland lake and recreational beach systems in the upper Midwestern United States. Sci. Total Environ. 2020, 722, 137846. [CrossRef]

6. $\quad$ Farkas, K.; Walker, D.I.; Adriaenssens, E.M.; McDonald, J.E.; Hillary, L.S.; Malham, S.K.; Jones, D.L. Viral indicators for tracking domestic wastewater contamination in the aquatic environment. Water Res. 2020, 181, 115926. [CrossRef] [PubMed]

7. Ryan, P.G.; Moore, C.J.; van Franeker, J.A.; Moloney, C.L. Monitoring the abundance of plastic debris in the marine environment. Philos. Trans. R. Soc. B 2009, 364, 1999-2012. [CrossRef]

8. Maes, T.; Barry, J.; Leslie, H.A.; Vethaak, A.D.; Nicolaus, E.E.M.; Law, R.J. Below the surface. Twenty-five years of seafloor litter monitoring in coastal seas of North West Europe (1992-2017). Sci. Total Environ. 2018, 630, 790-798. [CrossRef]

9. Blettler, M.C.M.; Ulla, M.A.; Rabuffetti, A.P.; Garello, N. Plastic pollution in freshwater ecosystems: Macro-, meso-, and microplastic debris in a floodplain lake. Environ. Monit. Assess. 2017, 189, 581. [CrossRef] [PubMed]

10. Harthun, M.; Hopf, T.; Mußbach, J.; Schilling, E. Flussgebietsübergreifende Stellungsnahme des NABU zu den Bewirtschaftungsplänen und den Maßnahmenprogrammen der Wasserrahmenrichtlinie; NABU Naturschutz Deutschland e.V., 2015; Available online: https: //www.nabu.de/imperia/md/content/nabude/lebendigefluesse/150622-nabu-stellungnahme_wrrl.pdf (accessed on 3 June 2021).

11. Wierzbicka, E. Novel methods of nitrate and nitrite determination-A review. J. Elem. 2020, 25, 97-106. [CrossRef]

12. Madikizela, L.M.; Ncube, S.; Chimuka, L. Analysis, occurrence and removal of pharmaceuticals in African water resources: A current status. J. Environ. Manag. 2020, 253, 109741. [CrossRef]

13. Waldschläger, K.; Lechthaler, S.; Stauch, G.; Schüttrumpf, H. The way of microplastic through the environment-Application of the source-pathway-receptor model (review). Sci. Total Environ. 2020, 713, 136584. [CrossRef]

14. Li, Z.; Deen, M.; Kumar, S.; Selvaganapathy, P. Raman spectroscopy for in-line water quality monitoring-Instrumentation and potential. Sensors 2014, 14, 17275-17303. [CrossRef] [PubMed]

15. Sarfo, D.; Sivanesan, A.; Emad, I.; Godwin, A. Rapid detection of mercury contamination in water by surface enhanced Raman spectroscopy. RSC Adv. 2017, 7, 21567-21575. [CrossRef]

16. Li, D.; Zhai, W.; Li, Y. Recent progress in surface enhanced Raman spectroscopy for the detection of environmental pollutants. Microchim. Acta 2014, 181, 23-43. [CrossRef]

17. Pfannkuche, J.; Lubecki, L.; Schmidt, H.; Kowalewska, G.; Kronfeldt, H. The use of surface-enhanced Raman scattering (SERS) for detection of PAHs in the Gulf of Gdańsk (Baltic Sea). Mar. Pollut. Bull. 2012, 64, 614-626. [CrossRef] [PubMed] 
18. Ong, T.; Blanch, E.; Jones, O. Surface Enhanced Raman Spectroscopy in environmental analysis, monitoring and assessment. Sci. Total Environ. 2020, 720, 137601. [CrossRef]

19. Li, G.; Chen, M.; Wei, T. Application of Raman Spectroscopy to Detecting Organic Contaminant in Water. In Proceedings of the IITA International Conference on Control, Automation and Systems Engineering, Zhangjiajie, China, 11-12 July 2009.

20. Hug, W.F.; Bhartia, R.; Tsapin, A.; Lane, A.; Conrad, P.; Sijapati, K.; Reid, R.D. Water \& surface contamination monitoring using deep UV laser induced native fluorescence and Raman spectroscopy. In Proceedings of the SPIE, 6378, Chemical and Biological Sensors for Industrial and Environmental Monitoring II, Boston, MA, USA, 25 October 2006.

21. Araujo, C.; Nolasco, M.; Ribeiro, A.; Ribeiro-Claro, P. Identification of microplastics using Raman spectroscopy: Latest developments and future prospects. Water Res. 2018, 142, 426-440. [CrossRef]

22. Persichetti, G.; Bernini, R. Water monitoring by optofluidic Raman spectroscopy for in situ applications. Talanta 2016, 155, 145-152. [CrossRef] [PubMed]

23. Lussier, F.; Thibault, V.; Charron, B.; Wallace, G.; Masson, J. Deep learning and artificial intelligence methods for Raman andsurface-enhanced Raman scattering. TrAC Trends Anal. Chem. 2020, 124, 115796. [CrossRef]

24. Smith, E.; Dent, G. Modern Raman Spectroscopy—A Practical Approach, 1st ed.; Wiley \& Sons: Chichester, UK, 2004.

25. Asher, S.A.; Johnson, C.R. A new selective technique for characterization of polycyclic aromatic hydrocarbons in complex samples: UV resonance Raman spectroscopy of coal liquids. Anal. Chem. 1984, 56, 2258-2261.

26. Hug, W.F.; Reid, M.R.; Nguyen, Q.; Bhartia, R.; Reid, R.D. A new, hand-held, 1 to $5 \mathrm{~m}$ standoff analyzer for real-time detection of trace chemical, biological, and explosives substances on surfaces, SPIE Defense \& Commercial Sensing. In Proceedings of the SPIE Defense \& Commercial Sensing, Vol. 11010, Chemical, Biological, Radiological, Nuclear, and Explosives (CBRNE) Sensing XX, 110100L, Baltimore, MD, USA, 15 May 2019.

27. Ianoul, A.; Coleman, T.; Asher, S. UV Resonance Raman Spectroscopic Detection of Nitrate and Nitrite in Wastewater Treatment Processes. Anal. Chem. 2002, 74, 1458-1461. [CrossRef] [PubMed]

28. DUV Raman PL200: Fully Integrated, Lab Model Deep UV Resonance Raman \& Photoluminescence Spectrometer, with Microscopic Imaging. Available online: https:/ / photonsystems.com/wp-content/uploads/2019/02/DUV-RamanPL200-DataSheet-V12-Web.pdf (accessed on 23 March 2020).

29. Liu, C. Implementation of Deep Ultraviolet Raman Spectroscopy. Ph.D.Thesis, Technical University of Denmark, Kongens Lyngby, Denmark, 2011.

30. Photon Systems Inc. New Deep UV Raman \& Photoluminescence Spectrometer System: The DUV Raman/PL 200. In Proceedings of the SPIE DCS 2018, Orlando, FL, USA, 16 April 2018.

31. Fused Fluorescence and Raman. Available online: https://photonsystems.com/technology/fused-fluorescence-and-raman/ (accessed on 9 March 2020).

32. Pohling, R. Chemische Reaktionen in der Wasseranalyse, 1st ed.; Springer Spektrum: Berlin/Heidelberg, Germany, 2015.

33. Beek, T.; Weber, F.; Bergmann, A. Pharmaceuticals in the Environment: Global Occurrence and Potential Cooperative Action under the Strategic Approach to International Chemicals Management (SAICM); Umweltbundesamt Texte, 67; 2016; Available online: https: / / www.umweltbundesamt.de/en/publikationen/pharmaceuticals-in-the-environment-global (accessed on 3 June 2021).

34. Dusi, E.; Rybicki, M.; Jungmann, D. The Database "Pharmaceuticals in the Environment"—Update and New Analysis; Umweltbundesamt Texte 67; 2019; Available online: https://www.umweltbundesamt.de/publikationen/the-database-pharmaceuticals-in-theenvironment (accessed on 3 June 2021).

35. Bergmann, A.; Fohrmann, F.; Weber, F.A. Zusammenstellung von Monitoringdaten zu Umweltkonzentrationen von Arzneimitteln; Umweltbundesamt Texte 66; 2011; Available online: https:/ / www.umweltbundesamt.de/publikationen/zusammenstellungvon-monitoringdaten-zu (accessed on 3 June 2021).

36. Fatta, D.; Achilleos, A.; Nikolaou, A. Analytical methods for tracing pharmaceutical residues in water and wastewater. Trends Anal. Chem. 2007, 26, 515-533. [CrossRef]

37. Wiesben, C.A. Raman-Mikrospektroskopie zur Analyse von Organischen Bodensubstanzen und Mikroplastik. Ph.D. Thesis, Technische Universität München, München, Germany, 2017.

38. Tetralog. Available online: www.tetralog.com (accessed on 6 May 2021).

39. Artha Vision, X. Available online: https:/ / www.artha-X.com/ (accessed on 21 December 2020).

40. Kniggendorf, A.K.; Wetzel, C.; Roth, B. Microplastics Detection in Streaming Tap Water with Raman Spectroscopy. Sensors 2019, 19, 1839. [CrossRef]

41. Heß, M.; Diehl, P.; Mayer, J.; Rahm, H.; Reifenhäuser, W.; Stark, J.; Schwaiger, J. Mikroplastik in Binnengewässern Süd- und Westdeutschlands. Teil 1: Kunststoffpartikel in der Oberflächennahen Wasserphase; LUBW/LfU Bayern/HLNUG/LANUV/LfU Rheinland-Pfalz: Karlsruhe, Germany; Augsburg, Germany; Wiesbaden, Germany; Recklinghausen, Germany; Mainz, Germany, 2018.

42. Hidalgo-Ruz, V.; Gutow, L.; Thompson, R.; Thiel, M. Microplastics in the marine environment: A review of the methods used for identification and quantification. Environ. Sci. Technol. 2012, 46, 3060-3075. [CrossRef] [PubMed]

43. Liu, Y.; Upadhyaya, B.; Naghedolfeizi, M. Chemometric Data Analysis Using Artificial Neural Networks. Appl. Spectrosc. 1993, 47, 12-23. [CrossRef]

44. Berghian-Grosan, C.; Magdas, D. Application of Raman spectroscopy and Machine Learning algorithms for fruit distillates discrimination. Sci. Rep. 2020, 10, 1-9. [CrossRef] 
45. Liu, J.; Osadchy, M.; Ashton, L.; Foster, M.; Solomone, C.; Gibson, S. Deep convolutional networks for Raman spectrum recognition: A unified solution. Analyst 2017, 142, 4067-4074. [CrossRef]

46. TensorFlow: An end-to-end Open Source Machine Learning Platform. Available online: https://www.tensorflow.org (accessed on 21 December 2020).

47. KnowItAll Spectroscopy Edition. Available online: https://sciencesolutions.wiley.com/knowitall-spectroscopy-software (accessed on 21 December 2020).

48. Free Spectral Database. Available online: https://spectrabase.com (accessed on 21 December 2020). 